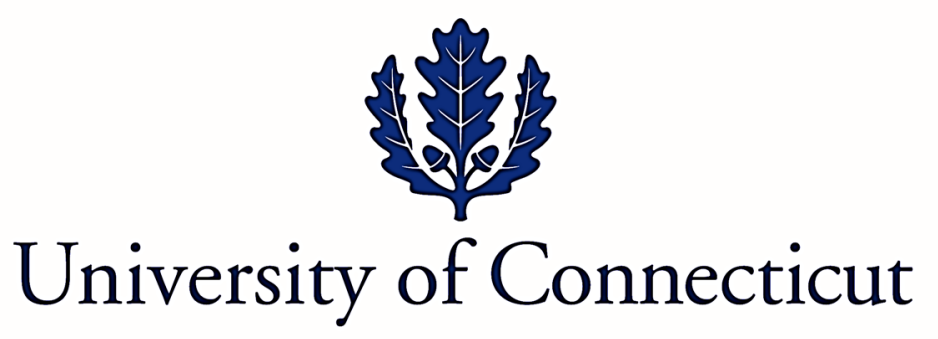

Department of Economics Working Paper Series

The Time-Varying Nature of Risk Aversion:

Evidence from 60 Years of U.S. Stock Market Data

by

Dominique Pépin

Université de Poitiers

Stephen M. Miller

University of Nevada - Las Vegas

Working Paper 2020-09

August 2020

365 Fairfield Way, Unit 1063

Storrs, CT 06269-1063

Phone: (860) 486-3022

Fax: (860) 486-4463

http://www.econ.uconn.edu/

This working paper is indexed in RePEc, http://repec.org 


\title{
The time-varying nature of risk aversion: Evidence from 60 years of U.S. stock market data
}

Dominique Pépin

CRIEF, Faculté de Sciences Economiques, Université de Poitiers, Poitiers, France. Email: dominique.pepin@univ-poitiers.fr

Stephen M. Miller*

Professor of Economics, Director, Center for Business and Economic Research, Lee Business School, Univeristy of Nevada, Las Vegas; Las Vegas, Nevada, USA. Email: stephen.miller@unlv.edu

JEL classification:

G10

G12

G17

Keywords:

Time-varying risk aversion

Price-dividend ratio

Short-term interest rate

Return predictors

\begin{abstract}
:
We investigate the time variations of the relative risk aversion parameter of a U.S. representative agent using 60 years of stock market data. We develop a methodology to identify the variables that explain the variations of risk aversion, based on an asset pricing model without valuation (or preference) risk. In this framework, the variables that predict the excess return of a market index (but not the second moments) also explain the variations of risk aversion. To wit, the variables include the price-dividend ratio and the short-term interest rate. A shock on the dividend-price ratio exerts a positive, highly persistent, though modest, effect on risk aversion, while a shock on the short-term interest rate exerts a highly negative, less persistent effect. The resulting measure of risk aversion follows a macroeconomically and financially countercyclical pattern.
\end{abstract}

* Corresponding author. 


\section{Introduction}

Individuals consume more ice cream in summer than in winter. They use umbrellas more on rainy days than on sunny days. These and other examples illustrate an undeniable characteristic of tastes: preferences are state-dependent. In the domain of financial economics, researchers increasingly focus on state-dependent preferences. Bakshi and Chen (1996), Campbell and Cochrane (1999), Gordon and St-Amour (2000), Brandt and Wang (2003), Melino and Yang (2003), Danthine et al.(2004), Gordon and St-Amour (2004), Menzly et al. (2004), Wachter (2006), Li (2007), Falato (2009), Bekaert et al. (2009; 2010), Greenwald et al. (2014), Kim(2014), Albuquerque et al. (2016) and Bekart et al. (2019) have all developed and estimated asset pricing models with state-dependent preferences. Merton (1973) and Cox et al. (1985) pioneered applications of state-dependent preferences to asset pricing. ${ }^{1}$ One particular case of state-dependent preferences, and our focus, involves the state-dependency of the relative risk aversion parameter. The existing literature reports more and more evidence that risk aversion is time-varying. Shocks to the risk aversion parameter significantly drive equity prices (Bekaert et al., 2009 and Greenwald et al., 2014), and significantly predict stock market crises (Coudert and Gex, 2008). Yet, the use of asset pricing models with time-varying risk aversion remains relatively rare, given the voluminous research work in finance, and researchers should know more about the state variables that affect risk preferences.

We propose a methodology to estimate the time-varying risk aversion of a representative agent, derived from an asset pricing model of Melino and Yang (2003). This model differs from the standard estimation of a time-varying risk aversion by adopting the recursive preferences framework of Epstein and Zin (1989) and Weil (1989), which separates intertemporal substitution and risk aversion. In our model, we make the additional special assumption of a

\footnotetext{
${ }^{1}$ In fact, Merton's model (1973) intended to study the effects of a stochastic investment opportunity set on asset pricing. But as Cox et al. (1985) and Ingersoll (1987) show, the model equivalently introduces stochastic processes in the opportunity set or in the preferences.
} 
constant elasticity of intertemporal substitution and a time-varying risk aversion parameter. This assumption rules out any possibility of valuation (or preference) risk. Indeed, asset pricing models with state-dependent risk aversion commonly give a substantial role to preference risk. That is, these models include a supplementary source of uncertainty, different from pure consumption uncertainty, that consists of the risk associated with changes in the discounting of future cash flows due to preferences shocks. ${ }^{2}$ Valuation risk creates a problem in that we cannot directly observe its existence. In practice, risk managers confront many different types of risk, but not with preference shocks. We differ from a large part of the existing models by adopting a theoretical framework that excludes any preference risk.

We also contribute to the literature by building a bridge between two strands of the financial literature: return predictability and time-varying risk aversion. The predictability literature documents that we can predict aggregate stock returns from past information, contrary to the strong version of the efficient markets hypothesis. At short horizons, return predictability proves less impressive, but we cannot ignore this phenomenon. Many established forecasts of predictive variables relate to the business cycle and predict countercyclical variations in stock returns (Fama and French, 1989 and Golez and Koudijs, 2018 ), echoing the countercyclical variation of risk aversion. Variations in expected stock returns may reflecct variations in the coefficient of risk aversion or in the risk level. If at date $t$, we know that the riskiness of stock returns or the risk aversion of the representative agent varies, then asset prices must vary to maintain equilibrium, inducing a change in expected returns and then a modification in the prediction of the future random return. In our framework, the variables that predict the returns of equities (in excess of the return on the risk-free asset) but not their volatily (and other higher moments) are the state variables that explain the time-variations of risk aversion. This outcome

\footnotetext{
${ }^{2}$ Albuquerque et al. (2016) define valuation risk in this way. They consider time-preferences shocks but we can define preference risk for any type of preferences shock, such as a shock on risk aversion.
} 
results from using an asset pricing model with a state-dependent risk aversion and a fixed elasticity of intertemporal substitution. As a result, the regression of the market excess return on the state variables provides a measure of risk aversion.

This methodology also benefits from not relying on some modern index or market instrument such as the VIX index (as in Bollerslev et al., 2011, Dreschler and Yaron, 2011 and Bekaert et al., 2013), which restricts the sample size of the analysis. For example, the VIX index provided by the Chicago Board of Options Exchange begins in January 1990. This methodology enables us to track the variations of risk aversion on a monthly basis over a period of sixty years, from 1959 to 2018, for the U.S. stock market.

Our main empirical results include the following. First we identify the predicting variables that affect risk aversion: the dividend-price ratio and the short-term nominal interest rate, which the literature identifies for their return predictability capabilities.

Second, we find strong support for the assumption that risk aversion is financially countercyclical. That is, risk aversion increases when the dividend-price ratio rises. This result proves consistent with studies that show risk aversion varying in response to stressful events, such as a drop in asset prices (see Schildberg-Hörisch, 2018 for a review). Risk aversion responds positively, extremely persistently, though modestly in magnitude, to a shock to the dividend price ratio.

Third and conversely, a shock to the short-term interest rate exerts a highly negative, but less persistent, effect on risk aversion. That a positive shock on the short-term interest rate leads to a decrease of risk aversion may seem surprising at first thought, as it is intuitively tempting to conclude that an accommodative monetary policy should decrease risk aversion (this is precisely what Beakert et al. (2013) conclude). But in the end, the data tell a different story. When the interest rate decreases, the risk premium increases. This remains a robust and long-standing finding in the financial literature. If the one-month bill rate increases, the nominal 
stock return decreases (Fama and Schwert, 1977 and Campbell, 1987), so that the risk premium decreases, too. This negative relationship between the nominal short-term interest rate and risk aversion certainly results from the countercyclical nature of monetary policy. The short-term interest rate provides a good indicator of the overall state of the economy and seems better able to predict risk aversion than other cyclical variables (like output growth), at least in linear models. As a result, our measure of risk aversion based on the dividend-price ratio and the risk free interest-rate proves strongly countercyclical as each period of increasing risk aversion invariably associates with a recession.

The rest of the paper unfolds as follows. Section 2 briefly describes the asset pricing models with time-varying risk aversion. Section 3 outlines the theoretical results of the paper and the empirical methodology to identify the variables that engender variations in risk aversion. Section 4 presents our empirical findings in a univariate framework. Section 5 extends the analysis to a multivariate setting to carry out impulse response function analysis. Section 6 concludes.

\section{Asset pricing models with time-varying risk aversion}

State-dependency of the relative risk aversion parameter appears in asset pricing models in a variety of ways: by introducing wealth in the utility function, by including habit formation in consumption-based models, or by assuming explicitely the state-dependency of risk aversion in a "classical" Consumption-CAPM model or in a model with recursive preferences.

Bakshi and Chen (1986) and Falato (2003) postulate that investors derive utility from both consumption and wealth. Bakshi and Chen (1986) introduce wealth in the utility function as investors care about relative social status. Wealth accumulation not only increases consumption rewards but also improves social status. If we define the status of an individual as the ratio of wealth to the social-wealth index, and if we use the conventional utility function, risk aversion increases when the individual's wealth decreases. Falato (2003) introduces wealth 
in the utility function to capture the idea that investors seek "happiness maintenance". An investor who experiences a favorable wealth shock becomes more risk-adverse, wanting to maintain the current wealth level. This specification of preferences leads to the unusual finding of procyclical risk aversion.

Campbell and Cochrane (1999), Brandt and Wang (2003), Menzly et al. (2004), Wachter (2006), Li (2007), and Bekaert et al. (2009, 2010, 2019) consider consumption-based models, including external habit formation. In such models, risk aversion is endogeneous to the relative level of consumption. When consumption declines toward the habit outcome, risk aversion rises. These articles differ by the law of motion they assume for the risk aversion or for the surplus consumption ratio (the difference between consumption and the external habit outcome, in proportion of consumption). Campbell and Cochrane (1999), Brandt and Wang (2003), Menzly et al. (2004), Wachter (2006), Li (2007), and Bekaert et al. (2009, 2010) assume that the law of motion relies on the consumption growth (or its innovation). Brandt and Wang (2003) assume that the process depends also on the inflation innovation and Bekaert et al. (2009, 2010, 2019) assume that it possesses its own innovation, a non-fundamental shock. Risk aversion's law of motion in Bekaert (2019) depends on two state variables that govern the timevarying conditional mean of the change in the logarithm of industrial production.To wit, it depends also on good and bad uncertainty shocks determined from the industrial production shock and on an orthogonal preference shock.

Gordon and St-Amour (2000, 2004), Danthine et al. (2004), and Greenwald et al. (2014) use the Consumption-CAPM framework of Lucas (1978) and Mehra and Prescott (1985). Gordon and St-Amour (2000) use a simple two-state (bull and bear markets) Markov process for describing the risk aversion law of motion. Gordon and St-Amour (2004) model risk aversion as a latent variable, which they model as a smooth diffusion process. Danthine et al. (2004) assume that the coefficient of risk aversion perfectly negatively correlates with 
consumption growth, which follows a two-state Markov process. Greenwald et al. (2014) assume that risk aversion is a logistic function (i.e., non-negative and bounded) of an $\mathrm{AR}(1)$ process.

Generalizing the Mehra and Prescott (1985) framework to a state-dependent risk aversion model proves troublesome because it engenders non-stationary returns, as the intertemporal rate of marginal substitution depends not only on the consumption growth rate but also on the level of consumption (Danthine et al., 2004 and Donaldson and Mehra, 2008). A solution to this problem separates time and risk preferences, using recursive preferences as in Epstein and Zin (1989) and Weil (1989). This class of preferences allows a disconnection of the coefficient of risk aversion and the elasticity of intertemporal substitution. In this framework, the intertemporal rate of marginal substitution no longer depends on the level of consumption (see Epstein, 1988 and Melino and Yang, 2003 for a derivation of the Euler equations), so that returns are stationary. Melino and Yang (2003) and Kim (2014) explore the countercyclicality of risk aversion in consumption-based models with recursive preferences. Melino and Yang (2003) analyse the effects of variations in risk aversion, along with considering variations in the subjective discount factor and in the elasticity of intertemporal substitution. They use a two-state Markov process to show the necessity of countercyclical risk aversion to fit the first two moments of asset returns. Kim (2014) proposes a non-parametric estimation of time-varying risk aversion conducted by a local-linear regression, based on a smoothness condition on the risk aversion parameter.

All these papers produce a broad consensus that models of asset pricing with statedependent risk aversion can explain many of the most noticeable characteristics of financial market data. Campbell and Cochrane (1999) show that countercyclical risk aversion provides the key to explaining a wide variety of dynamic asset pricing puzzles. Gordon et St-Amour (2000, 2004), Brandt and Wang (2003), Melino and Yang (2003), Kim (2014), and Bekaert et 
al. (2010, 2019) also present evidence for countercyclical risk aversion. Bekaert and Hoerova (2016) develop a measure of risk aversion inspired by the asset pricing literature that also proves countercyclical.

The empirical results of these asset pricing models conform to those from individual behavioral studies based on panel data. Bucciol and Miniaci (2018) examine self-reported attitudes towards financial risk-taking of Dutch households as a function of GDP, market returns, and unemployment rates. Sahm (2012) studies hypothetical gambles on lifetime income of older U.S. adults (age 40-75) as a function of the Index of Consumer Sentiment. Both studies confirm the idea that individuals are more risk-tolerant during periods of expansion and are more risk-averse during periods of recession.

Falato (2009) provides a rare dissenting opinion, which shows that a model with procyclical changes in risk aversion can prove consistent with data. Li (2007) expresses a skeptical view on the ability of a countercyclical risk aversion to explain aggregate stock market return behaviour.

Countercyclicality of risk aversion possesses a simple intuitive explanation: investors willingly invest in risky assets during economic booms, which induces a decline of the risk premium (and an increase of the risk-free rate due to the backflow of precautionary saving). Conversely, investors prefer to invest in risk-free assets during recessions, leading to an increase of the risk premium (and a decrease of the risk-free rate). Cochrane (2017) outlines the importance of countercyclical risk aversion in business cycle analysis. When investors fear purchasing risky assets, businesses stop investing and consumers stop consuming because of their fear. Understanding the time variations of risk aversion and identifying the variables that govern the risk aversion of a representative agent, thus, proves critical not only for financial economics but also for macroeconomics. 
There remains considerable scope for analysis on this issue, as models with statedependent risk aversion remain rare. Moreover, many of these models assume, often implied, that agents are subject to preference risk. Indeed, time-varying risk aversion under a timeadditive expected utility model induces valuation risk. In a model where the coefficient of relative risk aversion equals the inverse of the elasticity of intertemporal substitution, time variations of the risk aversion parameter engender a more complicated intertemporal marginal rate of substitution, which depends on both the present and the one-period ahead risk aversion coefficients (Danthine et al., 2004 and Donaldson and Mehra, 2008). The representative agent is, thus, concerned with the possible changes in his risk aversion parameter. The risk associated with shocks to this parameter constitute a preference risk for the agent, which induces hedging behavior and affects the equilibrium returns of assets. In fact, the problem is not that the risk aversion varies; the problem comes from the variations of the elasticity of intertemporal substitution. In a model where the two parameters are disconnected and both are statedependent, Melino and Yang (2003) show that the intertemporal marginal rate of substitution depends not only on the current risk aversion parameter but also on the current and the oneperiod ahead elasticity of intertemporal substitution. In fact, the variations of this last parameter generate preference risk.

Consumption-based models with habit formation induce valuation risk, too. Brandt and Wang (2003) develop an unconditional factor model representation with habit persistence and show that the risk premium consists of two parts: the return covariance with consumption growth, the classical consumption risk premium, and the return covariance with changes in risk aversion, a supplementary premium due to preference risk.

More generally, Merton's model (1973) shows that assets demand and expected equilibrium returns respond to the possibility of uncertain changes in preferences. He derives that state dependency induces additional hedging portfolios in the agent's demand for assets. 
The agents try to hedge against variations of their preferences and they willingly hold assets exposed to preference risk only if they pay a supplementary premium. The problem of preference risk is simply that there is no direct observation that it exists. We can observe that agents hedge against market risk, interest risk, exchange risk, default risk, and so on. But no direct observation exists that agents try to hedge against preference risk. This is why we propose to investigate state-dependent risk aversion in a model without preference risk. A simple way to rule out any valuation risk simply assumes a time-varying risk aversion model with recursive preferences with a fixed elasticity of substitution. ${ }^{3}$

\section{Theory and methodology}

Our empirical methodology uses a theoretical asset pricing model that disconnects the risk aversion parameter and the elasticity of intertemporal substitution, as in Epstein and Zin (1989) and Weil (1989). Melino and Yang (2003) and Kim (2014) also employ this recursive preferences framework. Melino and Yang (2003) explore the effects of state-dependent preferences on asset pricing. The risk aversion parameter, the subjective discount factor, and the elasticity of intertemporal substitution are all state-dependent and they use a two-state Markov process to explain the equity premium puzzle. They do not try to identify the state variables that can explain the variations of risk aversion, which is our objective. Our approach comes closer to Kim (2014), but differs on two importants respects. First, Kim (2014) simplifies the Euler equations by assuming that the optimal portfolio is the market portfolio, so that $\mathrm{R}_{\mathrm{c}, \mathrm{t}+1}=\mathrm{R}_{\mathrm{d}, \mathrm{t}+1}$ in the equations hereafter. $\mathrm{R}_{\mathrm{c}, \mathrm{t}+1}$ is the gross real return of the optimal portfolio (i.e., the portfolio that delivers aggregate consumption as its dividends each period) and $R_{d, t+1}$ is the real return of some proxy of the market portfolio. Second, the non-parametric estimation of time-varying risk aversion proposed by Kim (2014) totally overlooks the predictability issue.

\footnotetext{
${ }^{3}$ Kim (2014) also develops a model with time-varying risk aversion and a fixed elasticity of substitution.
} 
Indeed, as we explain in more detail below, the time-varying risk aversion parameter in a recursive preferences framework predicts returns.

Consider an endowment economy inhabited by an infinitely-lived representative agent who receives utility from the consumption $C_{t}$ of a single perishable good at date $t$. The life-time utility $U_{t}$ of the agent is a generalized version of the Epstein-Zin-Weil recursive utility function, allowing the representative agent to display state-dependent risk aversion

$$
\mathrm{U}_{\mathrm{t}}=\left[(1-\beta) \mathrm{C}_{\mathrm{t}}^{1-\rho}+\beta \mathrm{E}\left(\mathrm{U}_{\mathrm{t}+1}^{1-\gamma_{\mathrm{t}+1}} / \Psi_{\mathrm{t}}\right)^{\frac{1-\rho}{1-\gamma_{\mathrm{t}+1}}}\right]^{\frac{1}{1-\rho}}
$$

where $\beta$ denotes a subjective discount factor, $\rho$ denotes the inverse of the elasticity of intertemporal substitution, $\gamma_{\mathrm{t}+1}$ denotes the stochastic relative risk aversion coefficient, and $\mathrm{E}\left(. / \Psi_{\mathrm{t}}\right)$ denotes the conditional expectation operator with respect to the relevant information set $\Psi_{\mathrm{t}}$ (which consists of all the forecasting variables whose values are known at the date $\mathrm{t}$ ). The relative risk aversion $\gamma_{\mathrm{t}+1}$ coefficient is time-varying while the elasticity of intertemporal substitution $1 / \rho$ is a constant.

The risk aversion coefficient $\gamma_{\mathrm{t}+1}$ is a predetermined parameter. Consider the time interval $[t, t+1]$ and denote $R_{t+1}$ as the random real return of an asset on this interval. $R_{t+1}$ is observed at date $t+1$ while the time-varying risk aversion $\gamma_{t+1}$ which affects the consumption and portfolio decisions over the same time interval $[\mathrm{t}, \mathrm{t}+1]$ is known at the beginning of the period at date $t$. So, variations in $\gamma_{\mathrm{t}+1}$ induce variations in the equilibrium asset price and in the equilibrium expected return in a predictable way. This is an important feature of our model, which differs on this point from models with habit persistence. In such models, the risk aversion is not a predetermined parameter as it depends on the level of consumption $\mathrm{C}_{\mathrm{t}+1}$ relatively to the habit persistence outcome. It is determined throughout the time interval $[t, t+1]$ and its value is known at the end of the period. Thus, it does not determine the consumption and portfolio decisions but rather these decisions and risk aversion are jointly determined. 
The intertemporal budget constraint of the representative agent is

$$
\mathrm{W}_{\mathrm{t}+1}=\mathrm{R}_{\mathrm{c}, \mathrm{t}+1}\left(\mathrm{~W}_{\mathrm{t}}-\mathrm{C}_{\mathrm{t}}\right)
$$

where $\mathrm{W}_{\mathrm{t}}$ is the representative agent's wealth.

Epstein and Zin $(1989,1991)$ and Weil (1989) derive the stochastic discount factor consistent with equation (2) when the risk aversion coefficient $\gamma_{t+1}$ is a constant $\gamma$. Melino and Yang (2003) show that the stochastic discount factor does not change when the risk aversion varies over time, but is state-dependent, except that the fixed risk aversion $\gamma$ is replaced with the time-varying state-dependent risk aversion parameter $\gamma_{t+1}$.

Consider the real return $\mathrm{R}_{\mathrm{d}, \mathrm{t}+1}$ of some proxy of the market portfolio, which represents a claim on the aggregate real dividend $D_{t}$, and the real return $R_{f, t+1}$ of the nominal riskless asset. Sometimes, the asset pricing literature assumes that the nominal riskless asset, whose nominal return is known in advance, is also riskless in real terms (e.g., Mehra and Prescott, 1985). We do not make this assumption, and so our methodology proves consistent with an inflation premium.

Equations (1) and (2) imply the following Euler equations

$$
\begin{aligned}
& E\left[\beta^{\frac{1-\gamma_{t+1}}{1-\rho}}\left(\frac{C_{t+1}}{C_{t}}\right)^{-\frac{\rho\left(1-\gamma_{t+1}\right)}{1-\rho}}\left(R_{c, t+1}\right)^{\frac{1-\gamma_{t+1}}{1-\rho}-1} R_{d, t+1} / \Psi_{t}\right]=1, \text { and } \\
& E\left[\beta^{\frac{1-\gamma_{t+1}}{1-\rho}}\left(\frac{C_{t+1}}{C_{t}}\right)^{-\frac{\rho\left(1-\gamma_{t+1}\right)}{1-\rho}}\left(R_{c, t+1}\right)^{\frac{1-\gamma_{t+1}}{1-\rho}-1} R_{f, t+1} / \Psi_{t}\right]=1
\end{aligned}
$$

Let $\mathrm{x}_{\mathrm{t}} \subset \Psi_{\mathrm{t}}$ denote the vector of variables that explain the time variation of the risk aversion parameter $\gamma_{t+1}$, such that $\gamma_{t+1}$ depends on $x_{t}: \gamma_{t+1}=\gamma\left(x_{t}\right)$. By the law of iterated expectation, we can rewrite equations (3) and (4) as follows:

$$
\begin{aligned}
& E\left[\beta^{\frac{1-\gamma_{t+1}}{1-\rho}}\left(\frac{C_{t+1}}{C_{t}}\right)^{-\frac{\rho\left(1-\gamma_{t+1}\right)}{1-\rho}}\left(R_{c, t+1}\right)^{\frac{1-\gamma_{t+1}}{1-\rho}-1} R_{d, t+1} / X_{t}\right]=1, \text { and } \\
& E\left[\beta^{\frac{1-\gamma_{t+1}}{1-\rho}}\left(\frac{C_{t+1}}{C_{t}}\right)^{-\frac{\rho\left(1-\gamma_{t+1}\right)}{1-\rho}}\left(R_{c, t+1}\right)^{\frac{1-\gamma_{t+1}}{1-\rho}-1} R_{f, t+1} / X_{t}\right]=1
\end{aligned}
$$


We assume as in the asset pricing literature since the seminal paper of Bansal and Yaron (2004) that $\rho<1$, which means that the elasticity of intertemporal substitution (the inverse of $\rho)$ exceeds one, so that $\lambda_{t+1}=\frac{\gamma_{t+1}-1}{1-\rho}$ positively correlates with $\gamma_{t+1}$. We use lowercase letters for logarithms:

$$
c_{t+1}=\log \left(C_{t+1}\right), r_{d, t+1}=\log \left(R_{d, t+1}\right), r_{c, t+1}=\log \left(R_{c, t+1}\right) \text {, and } r_{f, t+1}=\log \left(R_{f, t+1}\right) \text {. }
$$

Assuming a normal distribution of the vector $\left(\mathrm{r}_{\mathrm{d}, \mathrm{t}+1}, \mathrm{r}_{\mathrm{c}, \mathrm{t}+1}, \Delta \mathrm{c}_{\mathrm{t}+1}\right)$ conditional on $\mathrm{x}_{\mathrm{t}}$, equations (5) and (6) become as follows:

$$
\begin{gathered}
-\lambda_{\mathrm{t}+1} \ln \beta+\rho \lambda_{\mathrm{t}+1} \mathrm{E}\left(\Delta \mathrm{c}_{\mathrm{t}+1} / \mathrm{x}_{\mathrm{t}}\right)-\left(\lambda_{\mathrm{t}+1}+1\right) \mathrm{E}\left(\mathrm{r}_{\mathrm{c}, \mathrm{t}+1} / \mathrm{x}_{\mathrm{t}}\right)+\mathrm{E}\left(\mathrm{r}_{\mathrm{d}, \mathrm{t}+1} / \mathrm{x}_{\mathrm{t}}\right) \\
+\frac{1}{2} \mathrm{~V}\left(\rho \lambda_{\mathrm{t}+1} \Delta \mathrm{c}_{\mathrm{t}+1}-\left(\lambda_{\mathrm{t}+1}+1\right) \mathrm{r}_{\mathrm{c}, \mathrm{t}+1} / \mathrm{x}_{\mathrm{t}}\right)+\frac{1}{2} \mathrm{~V}\left(\mathrm{r}_{\mathrm{d}, \mathrm{t}+1} / \mathrm{x}_{\mathrm{t}}\right) \\
+\operatorname{Cov}\left(\rho \lambda_{\mathrm{t}+1} \Delta \mathrm{c}_{\mathrm{t}+1}-\left(\lambda_{\mathrm{t}+1}+1\right) \mathrm{r}_{\mathrm{c}, \mathrm{t}+1}, \mathrm{r}_{\mathrm{d}, \mathrm{t}+1} / \mathrm{x}_{\mathrm{t}}\right)=0, \text { and } \\
-\lambda_{\mathrm{t}+1} \ln \beta+\rho \lambda_{\mathrm{t}+1} \mathrm{E}\left(\Delta \mathrm{c}_{\mathrm{t}+1} / \mathrm{x}_{\mathrm{t}}\right)-\left(\lambda_{\mathrm{t}+1}+1\right) \mathrm{E}\left(\mathrm{r}_{\mathrm{c}, \mathrm{t}+1} / \mathrm{x}_{\mathrm{t}}\right)+\mathrm{E}\left(\mathrm{r}_{\mathrm{f}, \mathrm{t}+1} / \mathrm{x}_{\mathrm{t}}\right) \\
+\frac{1}{2} \mathrm{~V}\left(\rho \lambda_{\mathrm{t}+1} \Delta \mathrm{c}_{\mathrm{t}+1}-\left(\lambda_{\mathrm{t}+1}+1\right) \mathrm{r}_{\mathrm{c}, \mathrm{t}+1} / \mathrm{x}_{\mathrm{t}}\right)+\frac{1}{2} \mathrm{~V}\left(\mathrm{r}_{\mathrm{f}, \mathrm{t}+1} / \mathrm{x}_{\mathrm{t}}\right) \\
+\operatorname{Cov}\left(\rho \lambda_{\mathrm{t}+1} \Delta \mathrm{c}_{\mathrm{t}+1}-\left(\lambda_{\mathrm{t}+1}+1\right) \mathrm{r}_{\mathrm{c}, \mathrm{t}+1}, \mathrm{r}_{\mathrm{f}, \mathrm{t}+1} / \mathrm{x}_{\mathrm{t}}\right)=0
\end{gathered}
$$

Note that the value of $\mathrm{r}_{\mathrm{f}, \mathrm{t}+1}$ does not appear in the information set $\mathrm{x}_{\mathrm{t}}$, even when the nominal return of the nominal riskless asset is known in advance, because the real return of the nominal riskless asset is random due to inflation during the time interval $[t, t+1]$. As a consequence, we cannot simplify equation (8) with respect to $r_{f, t+1}$.

Substracting equation (8) from equation (7) gives:

$$
\begin{gathered}
E\left(r_{d, t+1}-r_{f, t+1} / x_{t}\right)+\frac{1}{2} V\left(r_{d, t+1} / x_{t}\right)-\frac{1}{2} V\left(r_{f, t+1} / x_{t}\right)= \\
\left(\lambda_{t+1}+1\right) \operatorname{Cov}\left(r_{c, t+1}, r_{d, t+1}-r_{f, t+1} / x_{t}\right)-\rho \lambda_{t+1} \operatorname{Cov}\left(\Delta c_{t+1}, r_{d, t+1}-r_{f, t+1} / x_{t}\right)
\end{gathered}
$$


Assume for the moment that all conditional variances and covariances of equation (7) are constant: $V\left(r_{d, t+1} / x_{t}\right)=\sigma_{r_{d}}^{2}, V\left(r_{f, t+1} / x_{t}\right)=\sigma_{r_{f}}^{2} \operatorname{Cov}\left(r_{c, t+1}, r_{d, t+1}-r_{f, t+1} / x_{t}\right)=\sigma_{r_{c}, r_{d}-r_{f}}$, $\operatorname{Cov}\left(\Delta \mathrm{c}_{\mathrm{t}+1}, \mathrm{r}_{\mathrm{d}, \mathrm{t}+1}-\mathrm{r}_{\mathrm{f}, \mathrm{t}+1} / \mathrm{x}_{\mathrm{t}}\right)=\sigma_{\mathrm{c}, \mathrm{r}_{\mathrm{d}}-\mathrm{r}_{\mathrm{f}}}$, and that the conditional expectation is a linear regression function: $E\left(r_{d, t+1}-r_{f, t+1} / x_{t}\right)=a+b^{\prime} x_{t}$. With these assumptions, equation (9) simplifies to the following:

$$
\mathrm{a}+\mathrm{b}^{\prime} \mathrm{x}_{\mathrm{t}}+\frac{1}{2} \sigma_{\mathrm{r}_{\mathrm{d}}}^{2}-\frac{1}{2} \sigma_{\mathrm{r}_{\mathrm{f}}}^{2}=\left(\lambda_{\mathrm{t}+1}+1\right) \sigma_{\mathrm{r}_{\mathrm{c}}, \mathrm{r}_{\mathrm{d}}-\mathrm{r}_{\mathrm{f}}}-\rho \lambda_{\mathrm{t}+1} \sigma_{\mathrm{c}, \mathrm{r}_{\mathrm{d}}-\mathrm{r}_{\mathrm{f}}}
$$

We can use this equation to infer the value of $\lambda_{t+1}$ as a function of $x_{t}$ :

$$
\lambda_{\mathrm{t}+1}=\left(\mathrm{a}+\mathrm{b}^{\prime} \mathrm{x}_{\mathrm{t}}+\frac{1}{2} \sigma_{\mathrm{r}_{\mathrm{d}}}^{2}-\frac{1}{2} \sigma_{\mathrm{r}_{\mathrm{f}}}^{2}-\sigma_{\mathrm{r}_{\mathrm{c}}, \mathrm{r}_{\mathrm{d}}-\mathrm{r}_{\mathrm{f}}}\right) /\left(\sigma_{\mathrm{r}_{\mathrm{c}}, \mathrm{r}_{\mathrm{d}}-\mathrm{r}_{\mathrm{f}}}-\rho \sigma_{\mathrm{c}, \mathrm{r}_{\mathrm{d}}-\mathrm{r}_{\mathrm{f}}}\right)
$$

We conjecture that $\sigma_{r_{c}, r_{d}-r_{f}} \geq \sigma_{c, r_{d}}-r_{f}$. Indeed, if risk aversion is state-independent and returns and consumption growth are i.i.d., these two covariances are equal. If not so, they differ, but the return of the consumption portfolio certainly correlates more with the return of the market portfolio than does consumption growth, because both returns react to the variations of risk aversion. As a consequence, $\sigma_{r_{c}, r_{d}-r_{f}}-\rho \sigma_{c, r_{d}-r_{f}}>0$ and we may use the linear regression function $a+b^{\prime} x_{t}$ a positive index of risk aversion, which we denote $r a_{t+1}$. We estimate the unknown parameters a and $b^{\prime}$ by regressing the excess returns $r_{d, t+1}-r_{f, t+1}$ onto $x_{t}$, the vector of predictive variables. From the estimates $\hat{a}$ and $\widehat{b}^{\prime}$, we obtain the estimate of $\mathrm{ra}_{\mathrm{t}+1}$ :

$$
\widehat{\mathrm{ra}}_{\mathrm{t}+1}=\hat{\mathrm{a}}+\widehat{\mathrm{b}}^{\prime} \mathrm{x}_{\mathrm{t}}
$$

Admittedly, this measure of risk aversion critically assumes that the variances and covariances of equation (9) are constant. The accuracy of this assumption depends on the definition of the vector $\mathrm{x}_{\mathrm{t}}$. This assumption will prove false if we include too many predictive variables in $\mathrm{x}_{\mathrm{t}}$, notably those not related to risk aversion. So, we must identify the good variables to form the vector $\mathrm{x}_{\mathrm{t}}$, which is an empirical issue. Basically, the risk premium of an asset depends on the risk aversion parameter and on its risk level. If the variances and covariances of equation (9) are constant, the risk quantity of the asset remains constant and the only source of variation of 
the expected excess return comes from the variation of risk aversion. Therefore, constancy of the variances and covariances of equation (9) implies that the predictive variables $x_{t}$ are the state variables that explain (only) the variations of risk aversion. ${ }^{4}$

Consider again $\Psi_{t}$, the largest vector of (nonredundant) predictive variables. This vector includes variables that forecast exclusively the risk aversion $\left(\mathrm{x}_{\mathrm{t}}\right)$, others that forecast exclusively the risk level $\left(\mathrm{y}_{\mathrm{t}}\right)$, and still other variables that forecast both $\left(\mathrm{z}_{\mathrm{t}}\right)$. If we consider these vectors as informations sets, then $\mathrm{x}_{\mathrm{t}}, \mathrm{y}_{\mathrm{t}}$, and $\mathrm{z}_{\mathrm{t}}$ form a partition of $\Psi_{\mathrm{t}}$. We need to consider two scenarios.

First, no variable forecasts both the risk aversion and the risk level: $z_{t}=\emptyset$. This scenario, common for the econometrician, only identifies the variables that predict the variations of excess returns, but not the volatilities of excess returns and consumption growth. These variables explain the time variations of risk aversion.

Second, some variables explain both the variations of risk aversion and of the risk level: $\mathrm{z}_{\mathrm{t}} \neq \varnothing$. In this case, the variables in $\mathrm{x}_{\mathrm{t}}$ only include a part of the variables that explain the variations of risk aversion. We must interpret the measure of risk aversion $\mathrm{ra}_{\mathrm{t}+1}$ based on $\mathrm{x}_{\mathrm{t}}$ as a smoothed measure of risk aversion.

Whatever the real scenario is, the method for identifying the variables that explain risk aversion is the following. We regress $r_{d, t+1}-r_{f, t+1}$ on a candidate vector $x_{t}^{c}$. Trimming the elements that do not exhibit significant effects and those that predict the conditional variances ${ }^{5}$ and covariances of the excess returns and consumption growth. The set of the remaining variables is $x_{t}$, and regression of $r_{d, t+1}-r_{f, t+1}$ on $x_{t}$ gives $\widehat{r a}_{t+1}$. If no variables remain in

\footnotetext{
${ }^{4}$ This does not mean that risk-price variation entirely reflects risk-aversion variation. A part of risk-price variation also reflects risk-quantity variation, but the variables that explain risk aversion and those that explain risk quantity differ.

${ }^{5}$ Since we do not have data on $r_{c, t+1}$ and $\Delta c_{t+1}$, we focus on the variance of $r_{d, t+1}$ to exclude the variables that can explain the variations of the risk level.
} 
$\mathrm{x}_{\mathrm{t}}^{\mathrm{c}}$ that prove significant and do not predict the second moments, the measure $\widehat{\mathrm{ra}}_{\mathrm{t}+1}$ is an estimate of the true risk aversion; if not, as a matter of precaution, it has to be considered as a smoothed measure of risk aversion.

\section{Univariate analysis}

\subsection{Data}

We rely on the predictability literature and on the risk aversion literature to form our candidate vector $x_{t}^{c}$. We regress $r_{d, t+1}-r_{f, t+1}$ on seven variables: the (lagged) excess return $r_{d, t}-r_{f, t}$, the nominal return of the short-term interest rate $\mathrm{i}_{\mathrm{S}, \mathrm{t}}$, the nominal return of a long-term interest rate $i_{L, t}$, the dividend-price ratio $d p_{t}$, the inflation rate $\pi_{t}$, the industrial production's growth rate $\mathrm{ip}_{\mathrm{t}}$, and the monetary agregate's growth rate $\mathrm{m}_{\mathrm{t}}$.

Our sample consists of monthly statistics from 1959M1 to 2018M6, covering almost 60 years of data. This extended sample includes more than 700 observations for analysing risk aversion. The small-sample biases in predictive regressions of stock returns initially documented by Stambaugh (1986) and Mankiw and Shapiro (1986) is considerably attenuated and we simply ignore it.

We use data from Kenneth R. French's data library ${ }^{6}$ to compute $r_{d, t+1}-r_{f, t+1}$ and $i_{s, t}$. The nominal return of the short-term interest rate $i_{S, t}$ is $100 \times \log \left(1+R f_{t} / 100\right)$ where $R f_{t}$ is the one-month Treasury bill rate. $r_{d, t+1}-r_{f, t+1}$ is simply calculated as $100 \times \log \left(1+R m_{t} / 100\right)-$ $100 \times \log \left(1+\mathrm{Rf}_{t} / 100\right)$, where $\mathrm{Rm}_{\mathrm{t}}$ is a proxy for nominal market return.

We use the online data of Robert Shiller ${ }^{7}$ to compute the nominal return of a long-term interest rate $i_{L, t}$ and the dividend-price ratio $d p_{t} \cdot i_{L, t}$ is calculated according to

\footnotetext{
${ }^{6}$ The online data of Kenneth French is available at www.mba.tuck.dartmouth.edu/pages/faculty/ken.french/data_library.html.

${ }^{7}$ The online data of Robert Shiller is available at http://www.econ.yale.edu/ shiller/data.htm.
} 
$100 \times \ln \left(1+\mathrm{LIR}_{t} / 100\right)$ where $\mathrm{LIR}_{\mathrm{t}}$ is the 10 -year Treasury constant maturity rate. The dividendratio $\mathrm{dp}_{\mathrm{t}}$ is simply computed as the difference $\log \left(\right.$ real dividend $\left.\mathrm{d}_{\mathrm{t}}\right)-\log ($ real price $\mathrm{t})$.

The inflation rate $\pi_{t}$, the industrial production's growth rate $\mathrm{ip}_{\mathrm{t}}$, and the monetary agregate's growth rate $\mathrm{m}_{\mathrm{t}}$ are computed according to the formulae $100 \times \log \left(\mathrm{x}_{\mathrm{t}}\right)-100 \times \log \left(\mathrm{x}_{\mathrm{t}-1}\right)$, where $\mathrm{x}_{\mathrm{t}}$ is respectively the Consumer Price Index (for all urban consumers), the industrial production (total index), and the M2 money stock (in billions of dollars). ${ }^{8}$ The real return $r_{d, t+1}$ is simply calculated as the difference of $100 \times \log \left(1+R m_{t} / 100\right)$ and $\pi_{t}$.

We do not include the consumption growth rate among our predictive variables because not seasonnally adjusted consumption data are unavailable over long horizons at a monthly frequence. The use of not seasonnally adjusted data avoids biases in forecasting analyses as seasonally adjusted data depend on the future. Fortunately, the consumption growth rate does not perform well in the predictability literature.

Motivations for including $\mathrm{r}_{\mathrm{d}, \mathrm{t}}-\mathrm{r}_{\mathrm{f}, \mathrm{t}}, \mathrm{i}_{\mathrm{s}, \mathrm{t}}, \mathrm{i}_{\mathrm{L}, \mathrm{t}}, \mathrm{dp}_{\mathrm{t}}, \pi_{\mathrm{t}}, \mathrm{ip}_{\mathrm{t}}$, and $\mathrm{m}_{\mathrm{t}}$ in the candidate vector $\mathrm{x}_{\mathrm{t}}^{\mathrm{c}}$ are as follows. Predictability of stock returns from lagged returns is well known and long established. Fama and French (1988a) and Poterba and Summers (1988) made contributions to the literature on this issue. The predictive ability depends on the horizon (stronger autocorrelation exists for long-horizon returns) and on the nature of the return (nominal, real, or excess returns). For one-month excess returns, we find weak, first-order autocorrelation over 60 years of monthly observations but the coefficient proves significant at the $5 \%$ significance level (Table 1).

Predictability of excess return from short-term $\left(\mathrm{i}_{\mathrm{S}, \mathrm{t}}\right)$ and long-term $\left(\mathrm{i}_{\mathrm{L}, \mathrm{t}}\right)$ interest rates is long established, too. Campbell (1987) and Fama and French (1989) make well-known contributions, establishing that excess returns are predictable from variables that measure the

\footnotetext{
${ }^{8}$ Data come from the Federal Reserve Economic Data of the Federal Reserve Bank of St-Louis available at www.fred.stlouisfed.org.
} 
state of the term structure. The use of $i_{S, t}$ as well as monetary stock's growth rate $m_{t}$, which proxies for monetary policy, reflects Bekaert et al. (2013), who find that an accommodating monetary policy decreases risk aversion. Stock traders use dividend yield to forecast stock returns. Modern statistial evidence documents that the dividend-price ratio $\mathrm{dp}_{\mathrm{t}}$ forecasts stock returns (e.g., Campbell and Shiller, 1988 and Fama and French, 1988b). Fama (1990) and Schwert (1990) present evidence that macroeconomic variables such as industrial production provide forecasting abilities for stock returns. Motivation for including $\pi_{t}$ in the predictive variables occurs in Brand and Wang (2003), who provide evidence that risk aversion reacts to news about inflation, and in Boucher (2006), who shows that inflation can predict real stock returns.

\subsection{The model selection}

Our forecasting model involves the specification of lags as the excess return should depend on past values of the predictive variables. We assume a general dynamic linear model with $\mathrm{p}$ lags. We regress $r_{d, t+1}-r_{f, t+1}$ on the past values $r_{d, t-h}-r_{f, t-h}, i_{s, t-h}, i_{L, t-h}, d p_{t-h}, \pi_{t-h}, i_{t-h}$, and $\mathrm{m}_{\mathrm{t}-\mathrm{h}}$ for $\mathrm{h}=0,1,2, \ldots, \mathrm{p}-1$. We also include in the regressors the present nominal risk-free interest rate $i_{s, t+1}$, as it is known at the beginning of the period $[t, t+1]$ and causes no endogeneity bias. ${ }^{9}$

We assume that all variables are stationnary. We overlook the debate about the nature of the highly persistent variables $\mathrm{i}_{\mathrm{S}, \mathrm{t}}$ and $\mathrm{dp}_{\mathrm{t}}$. Some authors show that these variables are nonstationnary; others, stationnary. The asset pricing literature typicallly assumes stationarity for these two variables and, thus, we opt this hypothesis. To select the best model, we regress using OLS $r_{d, t+1}-r_{f, t+1}$ onto the predictors for $p=0,1,2, \ldots, 10$ and we select the model with

\footnotetext{
${ }^{9}$ More precisely, $\mathrm{i}_{\mathrm{s}, \mathrm{t}+1}$ is an end of month interest rate. That is, the valeur of the interest rate $\mathrm{i}_{\mathrm{s}, \mathrm{t}+1}$ for January is known at the end of December. As a consequence, $\mathrm{i}_{\mathrm{s}, \mathrm{t}+1}$ is known a little before $\mathrm{ra}_{\mathrm{t}+1}$, whose value is known at the beginning of January. Thus, $\mathrm{i}_{\mathrm{s}, \mathrm{t}+1}$ can be treated as a strictly exogenous variable when we regress $\mathrm{ra}_{\mathrm{t}+1}$ on it.
} 
the lowest corrected Akaike Information Criteria (AICc) of Hurvich and Tsai (1989). The results appear in Table 2.

The lowest AICc scores occur for $p=1$ and the scores strictly increase for $p>1$. The consequent selected model is as follows:

$$
\begin{gathered}
r a_{t+1}=a_{0}+a_{1} i_{s, t+1}+a_{2} i_{S, t}+a_{3} d p_{t}+a_{4} i_{L, t}+a_{5} \pi_{t}+a_{6} i p_{t} \\
+a_{7} m_{t}+a_{8}\left(r_{d, t}-r_{f, t}\right),
\end{gathered}
$$

where we estimate the parameters $\mathrm{a}_{0}, \mathrm{a}_{1}, \ldots, \mathrm{a}_{8}$ from the regression model:

$$
\begin{array}{r}
r_{d, t+1}-r_{f, t+1}=a_{0}+a_{1} i_{S, t+1}+a_{2} i_{S, t}+a_{3} d p_{t}+a_{4} i_{L, t}+a_{5} \pi_{t} \\
+a_{6} i_{t}+a_{7} m_{t}+a_{8}\left(r_{d, t}-r_{f, t}\right)+\varepsilon_{t+1}
\end{array}
$$

These selected forecasting regressors are also used to test the homoskedasticity hypothesis:

$$
\begin{gathered}
V\left(r_{d, t+1} / x_{t}\right)=\sigma_{r_{d}}^{2}, V\left(r_{f, t+1} / x_{t}\right)=\sigma_{r_{f}}^{2}, \\
\operatorname{Cov}\left(r_{c, t+1}, r_{d, t+1}-r_{f, t+1} / x_{t}\right)=\sigma_{r_{c}, r_{d}-r_{f}}, \text { and } \\
\operatorname{Cov}\left(\Delta c_{t+1}, r_{d, t+1}-r_{f, t+1} / x_{t}\right)=\sigma_{c, r_{d}-r_{f}} .
\end{gathered}
$$

To test the hypothesis $V\left(r_{d, t+1} / x_{t}\right)=\sigma_{r_{d}}^{2}$, we run a regression of $r_{d, t+1}$ on the forecasting variables and then test the homoskedasticity on the residuals. To test the hypothesis $\mathrm{V}\left(\mathrm{r}_{\mathrm{f}, \mathrm{t}+1} / \mathrm{x}_{\mathrm{t}}\right)=\sigma_{\mathrm{r}_{\mathrm{f}}}^{2}$, we note that $\mathrm{V}\left(\mathrm{r}_{\mathrm{f}, \mathrm{t}+1} / \mathrm{x}_{\mathrm{t}}\right)=\mathrm{V}\left(\pi_{\mathrm{t}+1} / \mathrm{x}_{\mathrm{t}}\right)$ as the nominal return of the shortterm risk free rate appears in the information set $x_{t}$. Thus, we run a regression of $\pi_{t+1}$ on the forecasting variables and test the homoskedasticity on the residuals of this regression. We cannot test directly the last two hypotheses as we do not observe $r_{c, t+1}$ and do not have data on $\Delta \mathrm{c}_{\mathrm{t}+1}$. If we assume, however, that the two correlation coefficients

$$
\begin{gathered}
\operatorname{Cov}\left(\mathrm{r}_{\mathrm{c}, \mathrm{t}+1}, \mathrm{r}_{\mathrm{t}+1} / \mathrm{x}_{\mathrm{t}}\right) / \sqrt{\mathrm{V}\left(\mathrm{r}_{\mathrm{c}, \mathrm{t}+1} / \mathrm{x}_{\mathrm{t}}\right) \mathrm{V}\left(\mathrm{r}_{\mathrm{t}+1} / \mathrm{x}_{\mathrm{t}}\right)} \text { and } \\
\operatorname{Cov}\left(\Delta \mathrm{c}_{\mathrm{t}+1}, \mathrm{r}_{\mathrm{t}+1} / \mathrm{x}_{\mathrm{t}}\right) / \sqrt{\mathrm{V}\left(\Delta \mathrm{c}_{\mathrm{t}+1} / \mathrm{x}_{\mathrm{t}}\right) \mathrm{V}\left(\mathrm{r}_{\mathrm{t}+1} / \mathrm{x}_{\mathrm{t}}\right)}
\end{gathered}
$$


with $r_{t+1}=r_{d, t+1}-r_{f, t+1}$ are constant, these two hypothesis require that $V\left(r_{d, t+1}-r_{f, t+1} / x_{t}\right)$ is a constant. This assumption can be tested with a homoskedasticity test on the residuals from regression equation (14).

\subsection{Estimating the time-varying risk aversion}

We begin by running a regression of $r_{d, t+1}-r_{f, t+1}$ on the candidate vector $x_{t}^{c}$ (equation 14) in order to investigate the forecasting capabilities of the candidate variables (Table 3). The shortterm interest rate and the dividend-price ratio exhibit significative forecasting abilities. The other variables exhibit no significant effects, even the lagged excess return, despite the observed significative, but small, autocorrelation in excess returns. That is, the parameters $\mathrm{a}_{4}, \mathrm{a}_{5}, \mathrm{a}_{6}, \mathrm{a}_{7}$, and $\mathrm{a}_{8}$ in equation (14) do not test significantly different from zero. The $\mathrm{R}^{2}$ of the regression is quite low, which is a standard result of returns forecasting regressions.

To test the homoskedasticity assumption, we run regressions not only of $r_{d, t+1}-r_{f, t+1}$ but also of $r_{d, t+1}$ and $\pi_{t+1}$ on the candidate forecasting variables. Then, we regress the squared residuals of these regressions on the same independent variables. Table 4 presents the results of these auxiliary regressions. We apply the Koenker's (1981) homoskedasticity test, which studentise the Breusch and Pagan's (1979) statistic to correct the significance levels for non Gaussian distributions.

The results of the homoskedasticity tests clearly show that the conditional variances $V\left(r_{d, t+1} / x_{t}\right), V\left(r_{f, t+1} / x_{t}\right)$, and $V\left(r_{d, t+1}-r_{f, t+1} / x_{t}\right)$ are not constants. By looking more closely at the results of these auxiliary regressions, we observe that $i_{S, t+1}, i_{S, t}$, and $d p_{t}$, which explain the variations of the conditional expected excess returns, do not explain the variations of the conditional variances. Rejection of the homoskedasticity hypothesis does not rely on the successful predicting variables. Rather, it mainly reflects $r_{d, t}-r_{f, t}$, and to a less extent $i_{L, t}$, ip $p_{t}$, and $\mathrm{m}_{\mathrm{t}}$. These variables, however, do not significantly predict excess returns, and we can 
remove them of the forecasting regression at little cost to generate the simplified regression equation:

$$
r_{d, t+1}-r_{f, t+1}=a_{0}+a_{1} i_{s, t+1}+a_{2} i_{s, t}+a_{3} d p_{t}+\varepsilon_{t+1}
$$

Table 5 presents the results of estimation of equation (15) and Table 6 presents the associated auxiliary regressions and homoskedasticity tests. The results of Table 5 confirm that $\mathrm{i}_{\mathrm{S}, \mathrm{t}+1}, \mathrm{i}_{\mathrm{S}, \mathrm{t}}$ and $\mathrm{dp} \mathrm{p}_{\mathrm{t}}$ significantly affect (forecast) $\mathrm{r}_{\mathrm{d}, \mathrm{t}+1}-\mathrm{r}_{\mathrm{f}, \mathrm{t}+1}$ and the results of Table 6 show that we cannot reject the null hypothesis of homoskedasticity at the $10 \%$ significance level. As a consequence, we can accept the assumption that the risk aversion is of the form:

$$
r a_{t+1}=a_{0}+a_{1} i_{S, t+1}+a_{2} i_{S, t}+a_{3} d p_{t}
$$

Risk aversion depends on monetary policy, as the short-term interest rate can be considered as a monetary policy instrument, and it depends also on the dividend-price ratio, which reflects the state of the financial cycle.

The negative value of the estimated parameter $\hat{a}_{1}$ means that a decrease of the shortterm interest rate instantaneously increases the risk aversion. This result opposes that of Beakert et al. (2013) who show that a lax monetary policy decreases risk aversion. In accordance with them, our results confirm the influence of monetary policy on risk aversion but our methodology based on the predictability of returns support the idea that monetary policy should exercise some procyclical influence on economic activity through the risk aversion transmission channel, which would reduce the effects of the traditional monetary policy transmission mechanism. ${ }^{10}$ This result may appear surprising given the risk-taking channel literature initiated by Borio and Zhu (2012). But the risk-taking attitude is not only driven by risk aversion, but

\footnotetext{
${ }^{10}$ This does not imply a procyclical monetary policy. A decrease of the interest rate exerts a countercyclical effect on economic activity, but the rise in risk aversion, which causes an increase of the risk premiuem, partly offsets this effect. The risk aversion transmission channel only makes monetary policy less effective.
} 
also by beliefs and the anticipated risk quantity. Thus, the relation between the interest rate and risk-taking does not reduce to the relation between the interest rate and risk aversion.

Accordingly, we note that risk aversion is a countercyclical variable, which rises in recessions. In recessions, the Federal Reserve lowers the short-term interest rate. In linear models, amongst all the macro-cyclical variables, the short-term interest rate certainly provides the best predictor of risk aversion, as it incorporates all information taken into consideration by the central banker. This may explain why we find a negative relationship between the shortterm interest rate and risk aversion. The short-term interest rate may simply capture the state of economy in a parsimonious way.

The positive value of the estimated parameter $\hat{a}_{2}$ dampens the negative effect of $\hat{a}_{1}$, but as successive variations of $i_{S, t}$ depend on each other, investigating the dynamical impact of $i_{S, t}$ on risk aversion requires a multivariate analysis, presented later (section 4). For now, observe that if we take expectations of both terms of equation (16), which simplifies to $\mathrm{E}\left(\mathrm{ra}_{\mathrm{t}+1}\right)=\mathrm{a}_{0}+$ $\left(a_{1}+a_{2}\right) E\left(i_{S, t+1}\right)+a_{3} E\left(d p_{t+1}\right)$, given stationary variables, the sum $a_{1}+a_{2}$ measures the effect of an increase of the long-term level of the short-term interest rate on the long-term level of risk aversion.

Table 7 indicates that the null hypothesis, $a_{1}+a_{2}=0$, is rejected at the $1 \%$ significance level. An increase of the long-term level of the short-term interest rate decreases the long-term level of risk aversion. Such a result, however, requires confirmation with multivariate analysis because the univariate analysis does not catch the indirect effect of the short-term interest rate on risk aversion through the dividend-price ratio. A shock to the short-term interest rate may affect the dividend-price ratio, which, in turn, may affect risk aversion.

Table 5 indicates also a strong influence of the dividend-price ratio on risk aversion. That is, risk aversion appears sensitive to the financial cycle. When the ratio rises, or when asset prices decline, risk aversion increases. Risk aversion is financially contercyclical. Psychologists 
show that this aspect of preferences may reflect an emotional response to a stressful event. According to Guiso et al. (2018), increases in risk aversion reflect a fear-induced phenomena caused by a scary experience. They administered a questionnaire to customers of an Italian bank in 2007, before the 2008 financial crisis, and in 2009, after the crisis, and analysed the responses. The bank's customers reported a lower certainty equivalent for a hypothetical lottery following the 2008 financial crisis. Cohn et al. (2015) confront financial professionals with either a boom or a bust scenario and measure their risk aversion in two experimental investment tasks with real monetary stakes. They find that subjects who were primed with a financial bust were substantially more risk averse than those who were primed with a boom. Gerrans et al. (2015), Dohmen et al. (2016), and Necker and Ziegelmeyer (2016) confirm that individuals who experience a financial crisis become more risk averse. The conclusion that emerges from these experimental studies is that the subjective willingness to take risks falls after a financial crisis. When asset prices decline, particularly for strong declines, individuals experience fear and anxiety (panic) and they behave with more risk aversion. Lerner and Keltner (2001), using correlation analysis, confirm that fear provides an important factor determining the level of risk aversion. That is, more fearful individuals are less willing to take risks in a hypothetical choice situation. Economic historians (e.g., Galbraith, 1997) document stock market panics as financial panics, by definition episods of intense fear. As financial instability increases, agents become more and more concerned about the future. Increased financial stress leads to the rise in their risk aversion. More generally, Malmendier and Nagel (2011) and Shigeoka (2019) highlight the importance of individual experience on the formation of risk preferences. Malmendier and Nagel (2011) show that individuals who experience low stock market returns throughout their lives report a lower willingness to take financial risk. Shigeoka (2019) finds that individuals who face hard economic conditions in youth become more risk averse in adulthood and that this effect is highly persistent. 
We view the financial countercyclicality of risk aversion as a survival mechanism based on experience. In effect, our endogenous preferences reflect our environment to increase our chance of survival. For example, you live on a remote island where fish is the only food; you must consume fish or you will die. This Darwinist point also suggests that, when facing serious danger, an individual's risk sensitivity increases to enable more efficient responses, such as a rush of adrenaline. That precisely captures what happens when the dividend-price ratio increases. When stock market declines, the risk sensitivity of agents (i.e., their risk aversion) increases so that they can react more quickly and strongly to escape the danger by selling their assets.

Figure 1 shows the evolution of the risk aversion measure $\widehat{r a}_{t+1}=\hat{a}_{0}+\hat{a}_{1} i_{S, t+1}+$ $\hat{\mathrm{a}}_{2} \mathrm{i}_{\mathrm{S}, \mathrm{t}}+\hat{\mathrm{a}}_{3} \mathrm{dp} \mathrm{p}_{\mathrm{t}}$ over the $1959-2018$ period and Table 8 reports simple descriptive statistics. Figure 1 identifies an important cyclicality in risk aversion. Moreover, the risk aversion volatility varies over time as the most important variations concentrate during the 1975-1990 period. That is, a part of the ex post returns heteroskedasticity comes from risk aversion. Table 8 confirms this, showing that both $\widehat{r a}_{t+1}$ and $r_{d, t+1}-r_{f, t+1}$ exhibits high kurtosis, which is symptomatic of heteroskedasticity in time series. Remember that the measure $\widehat{r a}_{t+1}$ is an affine function of the coefficient of relative risk aversion $\gamma_{t+1}$ so that the mean or median tell us nothing about the magnitude of the long-term risk aversion value. We do observe, however, that the maximum and minimum values of $\widehat{r a}_{t+1}$ exhibit highly positive and highly negative values, respectively. The maximum value of 3.5982 indicates the highest level of excess returns that we can explain by the forecasting variables. Since we measure returns in percent on a monthly basis, this is a very large value. In the same way, the minimum value of -3.7560 is also highly negative. The standard deviation of $\widehat{\mathrm{ra}}_{\mathrm{t}+1}$, which we can interpret as the standard deviation of the excess return explained by the risk aversion, takes the non-trivial value of 
0.7588 percent per month, which is still a small part of the total standard deviation of $r_{d, t+1}-$ $r_{f, t+1}$.

Figure 1 also shows periods of high and low risk aversion, where risk aversion sometimes declines or rises for years, a feature of an autocorrelated process. Three long periods of declining risk aversion stand out: the sixties, the nineties, and 2003-2007. A slower downward trend of risk aversion exists in the sixties than in the two other periods. Risk aversion declines in the sixties while the stock market rises. The first oil crisis ended the risk aversion decline and the bull market. The decrease of risk aversion in the nineties corresponds to the second longest recorded expansion in U.S. history and the dotcom bubble. The burst of the bubble in the early 2000s ended the risk aversion decline. The 2003-2007 period corresponds to the financial bubble between two major financial crises the dotcom bubble and the subprime crisis. Figure 1 also shows that the two periods of increasing risk aversion bookend the third period of decline in risk aversion from 2003-2007 and coincide with the two financial crises of the dotcom and subprime crises.

Figures 2 and 3 plot the time series of risk aversion with the interest component, $\mathrm{ic}_{\mathrm{t}+1}=$ $\hat{\mathrm{a}}_{1} \mathrm{i}_{\mathrm{S}, \mathrm{t}+1}+\hat{\mathrm{a}}_{2} \mathrm{i}_{\mathrm{S}, \mathrm{t}}$, and the dividend-price ratio component, $d p c_{t+1}=\hat{\mathrm{a}}_{0}+\hat{\mathrm{a}}_{3} \mathrm{dp} \mathrm{p}_{\mathrm{t}}$, respectively. We see that variations in the short-term interest rate are more important than variations in the dividend-price ratio in explaining the variations in risk aversion. Correlations confirm this observation. The correlation coefficient between the interest rate component and risk aversion is 0.754 whereas the correlation between the dividend-price component and the risk aversion is only 0.219 . The strong volatility of risk aversion during the $1975-1990$ period mirrors the strong volatility of the interest rate. Figure 3 also shows that the dividend-price ratio declined in the second half of the nineties and remained at a low level since then. The low dividend-price ratio observed in the last two decades puts downward pressure on risk aversion while the low level of interest rates puts upward pressure on risk aversion. Figure 2 also illustrates that risk aversion 
became less volatile since the beginning of the 2000 s as the result of the decrease of the shortterm interest rate volatility.

Finally, we examine the macroeconomic relevance of our measure of risk aversion. Figure 4 plots the smoothed risk aversion RAHP $^{11}$ with the NBER recession indicator RI. ${ }^{12}$ The link beween risk aversion and the business cycle is strong and obvious. The figure shows that periods of increasing risk aversion all associate with a recession. The process is always the same. The risk aversion begins increasing, and then the economy enters a recession. As the economy recovers from the recession, risk aversion decreases. Risk aversion is, thus, countercyclical and, above all, the inital rise of risk aversion provides a harbinger of recession. This result confims the view that understanding the time-varying movement of risk aversion and the risk premium proves crucial for macroeconomics (Cochrane, 2017).

\subsection{An autoregressive structure on risk aversion: A robustness analysis}

The observation of cyclical variations in risk aversion suggests that $\mathrm{ra}_{\mathrm{t}+1}$ is an autocorrelated process. Table 9 confirms this, showing that the estimated first-order autocorrelation of $\widehat{r a}_{t+1}$ is 0.424 and significant at the $1 \%$ level.

One can ask whether dependency of risk aversion on its past value completely explains the autocorrelation of the forecasting variables or whether the imposition of an autoregressive structure on risk aversion offers an alternative explanation, such as in Bekaert et al. (2009, 2010, 2019) and Bekaert and Hoerova (2016). We examine this issue by considering the generalized model of risk aversion:

$$
\begin{aligned}
& r_{d, t+1}-r_{f, t+1}=r a_{t+1}+\varepsilon_{t+1} \text {, and } \\
& r a_{t+1}=a_{0}+\theta r a_{t}+a_{1} i_{s, t+1}+a_{2} i_{s, t}+a_{3} d p_{t},
\end{aligned}
$$

\footnotetext{
${ }^{11}$ For RAHP, we use the Hodrick-Prescott filter smoothed series extracted from the risk aversion with $\lambda=$ 14,400 .

12 The recession dummy variable equals 1 during a recession and 0 during an expansion. Data come from the Federal Reserve Economic Data of the Federal Reserve Bank of St-Louis (series USREC).
} 
where $\mathrm{ra}_{\mathrm{t}}$ is an additional independent variable alongside with the previously determined forecasting variables.

As $\mathrm{ra}_{\mathrm{t}}$ is an unobserved independent variable, we cannot simply estimate by OLS the parameters of equation (18) as we did in the previous paragraph. We estimate the state-space model composed of equations (17) and (18) by maximum-likelihood method (Table 10). ${ }^{13}$

Table 10 reports that the estimated coefficient $\widehat{\theta}=-0.0447$ is not significant. Adding the lagged risk aversion in the model proves irrelevant. The short-term interest rate and the dividend-price ratio are persistent enough to engender an autocorrelated risk aversion without relying on a supplementary unobserved variable.

\section{Multivariate Analysis}

The dividend-price ratio and the short-term interest rate affect the risk premium, but we can also model $\mathrm{dp}_{\mathrm{t}}$ as depending on risk aversion. Moreover, $\mathrm{dp}_{\mathrm{t}}$ and $\mathrm{i}_{\mathrm{S}, \mathrm{t}}$ are autocorrelated processes so that we need to model their dynamics to measure the effect of monetary policy and stock market shocks on risk aversion. To this end, we model and estimate a system of equations with $\mathrm{ra}_{\mathrm{t}}, \mathrm{dp}_{\mathrm{t}}$, and $\mathrm{i}_{\mathrm{S}, \mathrm{t}}$ as endogeneous variables.

\subsection{The dividend-price ratio and the monetary policy rule equations}

The first step in modeling a system of equations specifies univariate equations for $d p_{t}$ and $i_{S, t}$. We draw on the monetary policy literature for the short-term interest rate and specify a Taylorrule equation:

$$
\mathrm{i}_{\mathrm{S}, \mathrm{t}+1}=\mathrm{b}_{0}+\mathrm{b}_{1} \mathrm{i}_{\mathrm{S}, \mathrm{t}}+\mathrm{b}_{2} i_{\mathrm{t}}+\mathrm{b}_{3} \pi_{\mathrm{t}}+\mathrm{u}_{\mathrm{t}+1} \text {. }
$$

\footnotetext{
${ }^{13}$ The starting coefficients values used in the iterative estimation procedure are zero for $\theta$ and the estimates of equation (16) for other parameters. We checked that the iterative algorithm did not stop at a local optimum by considering various starting values, in particular as regards the initial value of $\theta$. The initial value of the unobserved risk aversion is treated as diffuse. It makes no difference if we simply use the mean of excess return as an initial value for risk aversion.
} 
The estimation of equation (19) shows that all the estimated parameters $\hat{b}_{0}, \hat{b}_{1}, \hat{b}_{2}$, and $\hat{b}_{3}$ are significant (Table 11). The policymaker raises the interest rate when the industrial production and/or the inflation rate increases as $\hat{b}_{2}$ and $\hat{b}_{3}$ are positive, and this rise of the interest rate spreads over time as $\hat{b}_{1}$ is positive and high. These results conform to common wisdom in the monetary policy literature.

The specification of a dividend-price ratio equation is more problematic because no consensus exists in the financial literature about the form of a dynamic model for $\mathrm{dp}_{\mathrm{t}+1}$. We begin by specifying a general model with the risk aversion parameter, the interest rate, and the past values of the dividend-price ratio as explanatory variables. The problem is that $\mathrm{ra}_{\mathrm{t}+1}, \mathrm{i}_{\mathrm{S}, \mathrm{t}+1}, \mathrm{i}_{\mathrm{S}, \mathrm{t}}$, and $\mathrm{dp} \mathrm{p}_{\mathrm{t}}$ are perfectly collinear according to equation (16), so that we cannot use them simultaneously to predict $\mathrm{dp}_{\mathrm{t}+1}$. Theoretical models of asset pricing suggest that risk aversion and the short-term interest rate are key factors for explaining the dividend-price ratio. So we rule out past values of the dividend-price ratio to avoide multicollinearity, and we add an autoregressive component to the error of the regression equation as follows:

$$
\begin{aligned}
& \mathrm{dp}_{\mathrm{t}+1}=c_{0}+\sum_{\mathrm{i}=0}^{\mathrm{p}} \mathrm{d}_{\mathrm{i}} \mathrm{ra}_{\mathrm{t}+1-\mathrm{i}}+\sum_{\mathrm{i}=0}^{\mathrm{p}} \mathrm{e}_{\mathrm{i}} \mathrm{i}_{\mathrm{s}, \mathrm{t}+1-\mathrm{i}}+\varepsilon_{\mathrm{t}+1}, \\
& \varepsilon_{\mathrm{t}+1}=\varphi_{1} \varepsilon_{\mathrm{t}}+\varphi_{2} \varepsilon_{\mathrm{t}-1}+\cdots+\varphi_{\mathrm{p}} \varepsilon_{\mathrm{t}+1-\mathrm{p}}+\eta_{\mathrm{t}+1} .
\end{aligned}
$$

To identify the order $\mathrm{p}$, we replace the unknown risk aversion $\mathrm{ra}_{\mathrm{t}+1}$ measure with the estimated risk aversion measure $\widehat{r a}_{t+1}$ drawn from univariate analysis of section 3 , and we estimate equation (20) for $\mathrm{p}=0,1,2, \ldots, 10$. We select the model with the lowest AICc score (Table 12).

The minimum AICc score occurs for $\mathrm{p}=1$ and it strictly increases for $\mathrm{p}>1$. The consequent selected model is as follows:

$$
\begin{gathered}
\mathrm{dp}_{\mathrm{t}+1}=\mathrm{c}_{0}+\mathrm{d}_{0} \mathrm{ra}_{\mathrm{t}+1}+\mathrm{d}_{1} \mathrm{ra}_{\mathrm{t}}+\mathrm{e}_{0} \mathrm{i}_{\mathrm{s}, \mathrm{t}+1}+\mathrm{e}_{1} \mathrm{i}_{\mathrm{s}, \mathrm{t}}+\varepsilon_{\mathrm{t}+1}, \\
\varepsilon_{\mathrm{t}+1}=\varphi_{1} \varepsilon_{\mathrm{t}}+\eta_{\mathrm{t}+1} .
\end{gathered}
$$


The estimates of equation (21) with $\mathrm{ra}_{\mathrm{t}+1}$ and $\mathrm{ra}_{\mathrm{t}}$ replaced with $\widehat{\mathrm{ra}}_{\mathrm{t}+1}$ and $\widehat{\mathrm{ra}}_{\mathrm{t}}$ appear in Table 13.

When we replace $\mathrm{ra}_{\mathrm{t}+1}$ and $\mathrm{ra}_{\mathrm{t}}$ with $\widehat{\mathrm{ra}}_{\mathrm{t}+1}$ and $\widehat{\mathrm{ra}}_{\mathrm{t}}$, the measurement errors in $\widehat{\mathrm{ra}}_{\mathrm{t}+1}$ and $\widehat{r a}_{t}$ do not affect the asymptotical properties of the estimators of the parameters of equation (21) insofar as $\widehat{\mathrm{ra}}_{\mathrm{t}+1}$ and $\widehat{\mathrm{ra}}_{\mathrm{t}}$ converge towards $\mathrm{ra}_{\mathrm{t}+1}$ and $\mathrm{ra}_{\mathrm{t}}$. As $\widehat{\mathrm{ra}}_{\mathrm{t}+1}$ and the instruments $\mathrm{i}_{\mathrm{S}, \mathrm{t}+1}$, $\mathrm{i}_{\mathrm{S}, \mathrm{t}}$, and $\mathrm{dp}_{\mathrm{t}}$ are perfectly colinear, two-stage least squares generates exactly the same estimates as "one-stage" least squares. The estimators of the variances of the estimated coefficients, however, are biased downward, ${ }^{14}$ pushing up the t-statistics to artificially high values for some parameters.

With this warning in mind, we observe that all estimated parameters except $\widehat{d}_{1}$ are significant. The dividend-price ratio responds positively to risk aversion, which is consistent with the view that asset prices decrease when risk aversion rises. The dividend-price ratio responds positively to the short-term interest rate, even if the positive current effect is partly offset by a negative lagged effect. This result is consistent with the view that asset prices decrease when the interest rate increases. Hence, the monetary policy exerts an influence over risk aversion through two channels: not only the direct channel described in the univariate analysis, but also the indirect dividend-price channel described by equation (21). A change in the interest rate engenders a change in the dividend-price ratio that, in turns, causes a change in risk aversion.

\subsection{The system estimation}

We employ system estimation to conduct impulse response analysis. ${ }^{15}$ Moreover, system estimation provides consistent estimates of the t-statistics for the dividend-price ratio equation

\footnotetext{
${ }^{14}$ The variances are biased downward because they do not take into account that $\hat{a}_{0}, \hat{a}_{1}, \hat{a}_{2}$, and $\hat{a}_{4}$ are estimated coefficients and not known values.

${ }^{15}$ Estimating confidence interval for the impulse response function requires estimated covariances of all the parameters pairs of the system. A system equation is thus necessary to get all these covariances.
} 
as it incorporates the fact that risk aversion is unobserved. The system consists of equations (16), (17), (19), and (21) renumbered as equations (22), (23), (24), and (25), respectively:

$$
\begin{aligned}
& \mathrm{r}_{\mathrm{d}, \mathrm{t}+1}-\mathrm{r}_{\mathrm{f}, \mathrm{t}+1}=\mathrm{ra}_{\mathrm{t}+1}+\varepsilon_{\mathrm{t}+1}, \\
& \mathrm{ra}_{\mathrm{t}+1}=\mathrm{a}_{0}+\mathrm{a}_{1} \mathrm{i}_{\mathrm{S}, \mathrm{t}+1}+\mathrm{a}_{2} \mathrm{i}_{\mathrm{s}, \mathrm{t}}+\mathrm{a}_{3} \mathrm{dp}_{\mathrm{t}}, \\
& \mathrm{i}_{\mathrm{s}, \mathrm{t}+1}=\mathrm{b}_{0}+\mathrm{b}_{1} \mathrm{i}_{\mathrm{S}, \mathrm{t}}+\mathrm{b}_{2} \mathrm{i}_{\mathrm{t}}+\mathrm{b}_{3} \pi_{\mathrm{t}}+\mathrm{u}_{\mathrm{t}+1}, \\
& \mathrm{dp}_{\mathrm{t}+1}=\mathrm{c}_{0}+\mathrm{d}_{0} \mathrm{ra}_{\mathrm{t}+1}+\mathrm{d}_{1} \mathrm{ra}_{\mathrm{t}}+\mathrm{e}_{0} \mathrm{i}_{\mathrm{s}, \mathrm{t}+1}+\mathrm{e}_{1} \mathrm{i}_{\mathrm{s}, \mathrm{t}}+\varepsilon_{\mathrm{t}+1}, \\
& \varepsilon_{\mathrm{t}+1}=\varphi_{1} \varepsilon_{\mathrm{t}}+\eta_{\mathrm{t}+1} .
\end{aligned}
$$

This system can be estimated by substituting equation (23) in equations (22) and (25) to form the following nonlinear equations system:

$$
\begin{gathered}
\mathrm{r}_{\mathrm{d}, \mathrm{t}+1}-\mathrm{r}_{\mathrm{f}, \mathrm{t}+1}=\mathrm{a}_{0}+\mathrm{a}_{1} \mathrm{i}_{\mathrm{S}, \mathrm{t}+1}+\mathrm{a}_{2} \mathrm{i}_{\mathrm{S}, \mathrm{t}}+\mathrm{a}_{3} \mathrm{dp}_{\mathrm{t}}+\varepsilon_{\mathrm{t}+1}, \\
\mathrm{i}_{\mathrm{S}, \mathrm{t}+1}=\mathrm{b}_{0}+\mathrm{b}_{1} \mathrm{i}_{\mathrm{S}, \mathrm{t}}+\mathrm{b}_{2} \mathrm{ip}_{\mathrm{t}}+\mathrm{b}_{3} \pi_{\mathrm{t}}+\mathrm{u}_{\mathrm{t}+1}, \\
\mathrm{dp}_{\mathrm{t}+1}=\mathrm{c}_{0}+\mathrm{e}_{0} \mathrm{i}_{\mathrm{S}, \mathrm{t}+1}+\mathrm{e}_{1} \mathrm{i}_{\mathrm{S}, \mathrm{t}}+\mathrm{d}_{0}\left(\mathrm{a}_{0}+\mathrm{a}_{1} \mathrm{i}_{\mathrm{S}, \mathrm{t}+1}+\mathrm{a}_{2} \mathrm{i}_{\mathrm{S}, \mathrm{t}}+\mathrm{a}_{3} \mathrm{~d} \mathrm{p}_{\mathrm{t}}\right)+ \\
\mathrm{d}_{1}\left(\mathrm{a}_{0}+\mathrm{a}_{1} \mathrm{i}_{\mathrm{S}, \mathrm{t}}+\mathrm{a}_{2} \mathrm{i}_{\mathrm{S}, \mathrm{t}-1}+\mathrm{a}_{3} \mathrm{dp}_{\mathrm{t}-1}\right)+\varepsilon_{\mathrm{t}+1}, \\
\varepsilon_{\mathrm{t}+1}=\varphi_{1} \varepsilon_{\mathrm{t}}+\eta_{\mathrm{t}+1} .
\end{gathered}
$$

We estimate this system by generalized method of moments (Table 14). Univariate estimates of the parameters serve as starting coefficient values for the iterative estimation algorithm. For each equation, we use an intercept and the regressors of the equations as instruments. By doing so, the model is just-identified.

Comparison of equations system estimates from Table 14 with univariates estimates from Tables 5, 11, and 13 shows that multivariate and univariate models give exactly the same estimates for the dependent variables $r_{d, t+1}-r_{f, t+1}$ and $i_{S, t+1}$. That is, the GMM estimator with independent variables as instruments is equivalent to the OLS estimator. Multivariate estimates of the regression function of $\mathrm{dp}_{\mathrm{t}+1}$ are very similar to the univariate estimates. The multivariate procedure, however, incorpoates the fact that risk aversion is unobserved and produces 
consistent t-statistics, which are much lower than their univariate counterparts for some parameters. Hence, we cannot reject the null hypothesis that $\hat{\mathrm{e}}_{1}$ equals zero, according to the multivariate framework. The multivariate estimate confirms that the price-dividend ratio responds significantly to $\mathrm{ra}_{\mathrm{t}+1}$, but not to $\mathrm{ra}_{\mathrm{t}}$. It also confirms the influence of monetary policy on $\mathrm{dp}_{\mathrm{t}+1}$ through as $\hat{\mathrm{e}}_{0}$, which proves significantly different from 0 .

\subsection{The impulse response analysis}

We conduct an impulse response analysis to measure the risk aversion's response to shocks in the dividend-price ratio and in the short-term interest rate. To do so, we treat $\eta_{t+1}$ and $u_{t+1}$ as innovations, which is supported by the low correlation $(-0.0102)$ between the two residuals $\hat{\eta}_{t+1}$ and $\hat{u}_{t+1}$ of the system estimation. The pattern of response of risk aversion to shocks in the dividend-price ratio and in the short-term interest rate appear in Figures 5 and 6, respectively.

We calculate the impulse response functions from the GMM estimates of Table 14 with the simplifying assumption that $d_{1}=0$. We derive from the equations system the impulse response functions (details appear in the appendix). We use the delta method to calculate standard deviations.

The analytical responses of risk aversion to unit shocks in the dividend-price ratio and in the short-term interest rate are as follows:

$$
\begin{aligned}
& \frac{\partial \mathrm{ra}_{\mathrm{t}+\mathrm{k}}}{\partial \eta_{\mathrm{t}}}=0 \text { for } \mathrm{k}=0 \text { and } \frac{\partial \mathrm{ra} \mathrm{a}_{\mathrm{t}+\mathrm{k}}}{\partial \eta_{\mathrm{t}}}=\mathrm{a}_{3} \frac{\left(\mathrm{a}_{3} \mathrm{~d}_{0}\right)^{\mathrm{k}}-\varphi_{1}^{k}}{\mathrm{a}_{3} \mathrm{~d}_{0}-\varphi_{1}} \text { for } \mathrm{k} \geq 1 \text {, and } \\
& \begin{aligned}
\frac{\partial \mathrm{ra}_{\mathrm{t}+\mathrm{k}}}{\partial \mathrm{u}_{\mathrm{t}}} & =\mathrm{a}_{1} \text { for } \mathrm{k}=0 \text { and } \\
\frac{\partial \mathrm{ra}_{\mathrm{t}+\mathrm{k}}}{\partial \mathrm{u}_{\mathrm{t}}}= & \mathrm{a}_{1}\left(\mathrm{~b}_{1}\right)^{\mathrm{k}}+\mathrm{a}_{2}\left(\mathrm{~b}_{1}\right)^{\mathrm{k}-1}+\mathrm{a}_{3}\left(\mathrm{a}_{1} \mathrm{~d}_{0}+\mathrm{e}_{0}\right) \frac{\left(\mathrm{a}_{3} \mathrm{~d}_{0}\right)^{\mathrm{k}}-\left(\mathrm{b}_{1}\right)^{\mathrm{k}}}{\mathrm{a}_{3} \mathrm{~d}_{0}-\mathrm{b}_{1}} \\
& +\mathrm{a}_{3}\left(\mathrm{a}_{2} \mathrm{~d}_{0}+\mathrm{e}_{1}\right) \frac{\left(\mathrm{a}_{3} \mathrm{~d}_{0}\right)^{\mathrm{k}-1}-\left(\mathrm{b}_{1}\right)^{\mathrm{k}-1}}{\mathrm{a}_{3} \mathrm{~d}_{0}-\mathrm{b}_{1}} \text { for } \mathrm{k} \geq 1 .
\end{aligned}
\end{aligned}
$$


To report easily understandable impuse response functions, we consider shocks to innovations equal to their standard errors (i.e, 0.0342 for $\eta_{t+1}$ and 0.0601 for $u_{t+1}$ ). Thus, the responses to unit shocks given by equations (29) and (30) are multiplied by 0.0342 and 0.0601 , respectively, to produce the impulse response functions (IRF) reported in Figures 5 and 6.

The response of risk aversion to a shock to the dividend-price ratio innovation is positive. The response function increases from $\mathrm{k}=0$ to $\mathrm{k}=4$ and then it decreases. The magnitude of the response is not high. At its maximum level (for $k=4$ ), the response of risk aversion to a standard shock to the dividend-price ratio innovation is 0.065 . That is, the increase in risk aversion induced by the shock produces a rise of the excess return of 0.065 per cent (on a monthly basis). This response is, in fact, quite modest. The most important (estimated) value of the innovation in the sample occured on October 2008, reaching a level of 0.2165 . This shock produces an increase (four months later) of only 0.4114 in the value of risk aversion. ${ }^{16}$

The response of risk aversion to a shock to the dividend-price ratio innovation is weak, but persistent. We see from Figure 5 that the effect of the shock dies out slowly. The response to the shock remains largely significant after 36 months, as the "zero response" does not yet fall inside the confidence interval. Our calculations show that the response is no longer significant after 83 months onward.

We see from Figure 6 that the response of risk aversion to a shock to the short-term interest rate innovation is negative. The response function monotically decreases (in absolute terms). The maximum level of the response occurs for $\mathrm{k}=0$. A standard shock to the short-term interest rate produces an instantaneous decrease of 0.6 in risk aversion, a large value. At the end of 1980, the value of innovation reached the extreme level of 0.3583. In comparison with the zero value of the innovation, this shock produced a instantaneous decrease of 3.5293 in the

\footnotetext{
${ }^{16}$ A simple application of the rule of three delivers the value $0.4114: 0.4114=\frac{0.2165}{0.0342} \times 0.065$.
} 
value of risk aversion. The magnitude of the response of risk aversion to a shock to monetary policy is, thus, important. It is much more important than a shock to the dividend-price ratio innovation. It decreases more quickly, however. The level of the response one month later is four times smaller than the level of the instantaneous response, and the response no longer proves significant after 23 months onward.

\subsection{The long-term risk aversion}

If we assume that risk aversion is a linear function of stationary variables, its long-term value equals a constant value of 0.435 (Table 8). The results of the univariate analysis conducted in section 3 suggest that the long-term value of $\mathrm{ra}_{\mathrm{t}+1}$ depends on the long-term values of $\mathrm{i}_{\mathrm{S}, \mathrm{t}+1}$ and $\mathrm{dp}_{\mathrm{t}+1}$. Taking the mathematical expectation of equations (23) to (25) gives three equations describing the relationships between the long-term values of the variables:

$$
\begin{aligned}
& E\left(\mathrm{ra}_{\mathrm{t}}\right)=\mathrm{a}_{0}+\left(\mathrm{a}_{1}+\mathrm{a}_{2}\right) \mathrm{E}\left(\mathrm{i}_{\mathrm{s}, \mathrm{t}}\right)+\mathrm{a}_{3} \mathrm{E}\left(\mathrm{dp}_{\mathrm{t}}\right), \\
& \mathrm{E}\left(\mathrm{i}_{\mathrm{s}, \mathrm{t}}\right)=\left[\mathrm{b}_{0}+\mathrm{b}_{2} \mathrm{E}\left(\mathrm{ip}_{\mathrm{t}}\right)+\mathrm{b}_{3} \mathrm{E}\left(\pi_{\mathrm{t}}\right)\right] /\left[1-\mathrm{b}_{1}\right], \text { and } \\
& \mathrm{E}\left(\mathrm{dp}_{\mathrm{t}}\right)=\mathrm{c}_{0}+\mathrm{d}_{0} \mathrm{E}\left(\mathrm{ra}_{\mathrm{t}}\right)+\left(\mathrm{e}_{0}+\mathrm{e}_{1}\right) \mathrm{E}\left(\mathrm{i}_{\mathrm{s}, \mathrm{t}}\right) .
\end{aligned}
$$

An exogenous variation of $\mathrm{E}\left(\mathrm{dp}_{\mathrm{t}}\right)$ affects the long-term value $\mathrm{E}\left(\mathrm{ra}_{\mathrm{t}}\right)$, if $\mathrm{a}_{3}$ is non zero. If $\hat{a}_{3}$ is significant, we conclude that the long-term value of risk aversion depends on the longterm value of the price-dividend ratio. Regarding the relationship between the long-term values of risk aversion and the interest rate, the multivariate analysis provides strong reservations to the findings of the univariate analysis. The univariate analysis focuses on equation (31) and simply evaluates $\left(a_{1}+a_{2}\right)$. Multivariate analysis brings equations (31) and (33) together. An exogenous change in $\mathrm{E}\left(\mathrm{i}_{\mathrm{S}, \mathrm{t}}\right)$ can exert not only a direct effect on risk aversion based on equation (31), but also an indirect effect through the influence of $\mathrm{E}\left(\mathrm{i}_{\mathrm{s}, \mathrm{t}}\right)$ on $\mathrm{E}\left(\mathrm{d} \mathrm{p}_{\mathrm{t}}\right)$ based on equation (33). Substituting equation (33) into equation (31) generates

$$
\mathrm{E}\left(\mathrm{ra}_{\mathrm{t}}\right)=\left\{\mathrm{a}_{0}+a_{3} c_{0}+\left[a_{1}+a_{2}+a_{3}\left(e_{0}+e_{1}\right)\right] \mathrm{E}\left(\mathrm{i}_{\mathrm{S}, \mathrm{t}}\right)\right\} /\left\{1-a_{3} d_{0}\right\}
$$


and, then

$$
\frac{\partial \mathrm{E}\left(\mathrm{ra}_{\mathrm{t}}\right)}{\partial \mathrm{E}\left(\mathrm{i}_{\mathrm{s}, \mathrm{t}}\right)}=\left\{a_{1}+a_{2}+a_{3}\left(e_{0}+e_{1}\right)\right\} /\left\{1-a_{3} d_{0}\right\}
$$

Table 15 shows the results of the test of the hypothesis that the condition in equaton (35) equals zero is negative but not significant at even the $10 \%$ significance level, indicating that the long-term risk aversion does not depend on the long-term value of the (short-term) interest rate. The positive indirect effect of $\mathrm{E}\left(\mathrm{i}_{\mathrm{S}, \mathrm{t}}\right)$ on $\mathrm{E}\left(\mathrm{ra}_{\mathrm{t}}\right)$ offsets its negative direct effect documented in the univariate analysis. In the long-term, the dividend-price ratio only affects the risk aversion.

\section{Conclusion}

We develop a methodology to estimate the time-varying relative risk-aversion parameter of a representative agent. The model, based on Melino and Yang (2003), adopts the recursive preferences framework of Epstein and Zin (1989) and Weil (1989). To rule out any preference risk, we assume that the elasticity of intertemporal substitution is constant while the risk aversion parameter is time-varying. In this framework, the variables that predict the returns of equities (in excess of the risk-free return) but not their volatily are the state variables that explain the time-variation of risk aversion.

We use this property to identify the predicting variables that affect the risk aversion. We show that these variables include the dividend-price ratio and the short-term nominal interest rate. The positive effect of the dividend-price ratio implies that risk aversion is financially countercyclical. That is, risk aversion rises as the dividend-price ratio rises. The impulse response analysis reveals that a shock to the dividend-price ratio exerts a positive and persistent, though modest, effect on risk aversion. The negative effect of a short-term shock to the interest rate on risk aversion provides a more surprising result. In fact, it certainly reflects the countercyclical monetary policy of the Federal Reserve. In recessions, the central bank lowers 
the interest rate while risk aversion rises, hence the negative relationship. We show that the response of risk aversion to a shock to the short-term interest rate exerts a large negative effect on risk aversion, although less persistent than a shock to the dividend-price ratio. Viewed from a long-term perspective, risk aversion depends on the dividend-price ratio but not on the interest rate. Finally, we find that the resulting measure of risk aversion proves (macroeconomically) countercyclical, because risk aversion increases invariably associate with a recession.

\section{References}

Albuquerque, R., Eichenbaum, M., Luo V.X., and Rebelo, S., (2016). Valuation risk and asset pricing. Journal of Finance 71, 2861-2904.

Bekaert, G., Engstrom, E.C., and Grenadier, S.R., (2010). Stock and bond returns with moody investors. Journal of Empirical Finance 17, 867-894.

Bekaert, G., Engstrom, E.C., and Xing, Y., (2009). Risk, uncertainty, and asset prices, Journal of Financial Economics 91, 59-82.

Bekaert, G., Engstrom, E.C., and Xu, N.R., (2019). The time variation in risk appetite and uncertainty. NBER Working Paper Series 25673.

Bekaert, G., and Hoerova, M., (2016). What do asset prices have to say about risk appetite and uncertainty? Journal of Banking and Finance 67, 103-118.

Bekaert, G., Hoerova, M., et Lo Duca, M., (2013). Risk, uncertainty and monetary policy. Journal of Monetary Economics 60, 771-788.

Bollerslev, T., Gibson, M., and Zhou, H., (2011). Dynamic estimation of volatility risk premia and investor risk aversion from option-implied and realized volatilities. Journal of Econometrics 160, 235-245.

Borio, C., and Zhu, H., (2012). Capital regulation, risk-taking and monetary policy: A missing link in the transmission mechanism? Journal of Financial Stability 8, 236-251.

Boucher, C., (2006). Stock prices, inflation and stock returns predictability. Finance 27, 71101.

Brandt, M.W., and Wang, K.Q., (2003). Time-varying risk aversion and unexpected inflation. Journal of Monetary Economics 50, 1457-1498.

Breusch, T.S., and Pagan, A.R., (1979). A simple test for heteroskedasticity and random coefficient variation. Econometrica 47, 1287-1294. 
Bucciol, A., and Miniaci, R., (2018). Financial risk propensity, business cycles and perceived risk exposure. Oxford Bulletin of Economics and Statistics 80, 160-83.

Campbell, J.Y., (1987). Stock returns and the term structure. Journal of Financial Economics 18, 373-399.

Campbell, J.Y., and Cochrane, J.H., (1999). By force of habit: A consumption-based explanation of aggregate stock market behavior. Journal of Political Economy 107, 205-251.

Campbell, J.Y., and Shiller, J.H., (1988). The dividend-price ratio and expectations of future dividends and discount factors. Review of Financial Studies 1, 195-228.

Cochrane, J.H., (2011). Presidential address: Discount rates. The Journal of Finance. 66, $1047-$ 108, 2011.

Cochrane J.H. (2017), Macro-finance, Review of Finance, 21, 945-985.

Cohn A., Engelmann J., Fehr E. and Maréchal M.A. (2015), Evidence for Countercyclical Risk Aversion: An Experiment with Financial Professionals, American Economic Review, $105,860-885$.

Coudert V. et Gex M. (2008), Does risk aversion drive financial crises? Testing the predictive power of empirical indicators, Journal of Empirical Finance, 15, 167-184.

Cox J.C., Ingersoll J.E. and Ross S. A. (1985), An intertemporal general equilibrium model of asset prices, Econometrica, 53, 363-384.

Danthine J-P., Donaldson J.B., Giannikos C. and Guirguis H. (2004), On the consequences of state dependent preferences for the pricing of financial assets, Finance Research Letters, $1,143-253$.

Dohmen, T., Lehmann, H., and Pignatti, N., (2016). Time-varying individual risk attitudes over the Great Recession: A comparison of Germany and Ukraine. Journal of Comparative Economics 44, 182-200.

Drechsler, I., and Yaron, A., (2011). What's vol got to do with it. Review of Financial Studies $24,1-45$.

Epstein, L.G., and Zin, S.E., (1989). Substitution, risk aversion, and the temporal behavior of consumption and asset returns: A theoretical framework. Econometrica 57, 937-969.

Epstein, L.G., and Zin, S.E., (1991). Substitution, risk aversion, and the temporal behavior of consumption and asset returns: An empirical analysis. Journal of Political Economy 99, 263-286.

Falato, A., (2009). Happiness maintenance and asset prices. Journal of Economic Dynamics \& Control 33, 1247-1262. 
Fama, E.F., (1990). Stock returns, expected returns and real activity. Journal of Finance 45, 1089-1108.

Fama, E.F., and French, K.R., (1988a). Permanent and temporary components of stock prices. Journal of Political Economy 96, 246-273.

Fama, E.F., and French, K.R., (1988b). Dividend yields and expected stock returns. Journal of Financial Economics 22, 3-25.

Fama, E.F., and French, K.R., (1989)., Business conditions and expected returns on stocks and bonds. Journal of Financial Economics 25, 23-49.

Fama, E.F., and Schwert, G.W., (1977). Asset returns and inflation. Journal of Financial Economics 5, 115-146.

Galbraith, J.K., (1997). The Great Crash 1929. Houghton Mifflin Harcourt, Boston.

Gerrans, P., Faff, R., and Hartnett, N., (2015). Individual Financial risk tolerance and the Global Financial Crisis. Accounting \& Finance 55, 165-85.

Golez, B., and Koudijs, P., (2018). Four centuries of returns predictability. Journal of Financial Economics 127, 248-263.

Gordon, S., and St-Amour, P., (2000). A preference regime model of bull and bear markets. American Economic Review 90, 1019-1033.

Gordon, S., and St-Amour, P., (2004). Asset returns and state-dependent risk preferences. Journal of Business \& Economic Statistics 22, 241-252.

Greenwald, D.L., Lettau, M., and Ludvigson, S.C., (2014). The origins of stock market fluctuations. NBER Working Paper 19818.

Guiso, L., Sapienza, P., and Zingales, L., (2018). Time varying risk aversion. Journal of Financial Economics 128, 403-421.

Hurvich, C.M., and Tsai, C.-L., (1989). Regression and time series model selection in small samples. Biometrika 76, 297-307.

Ingersoll, J.E., (1987). Theory of Financial Decision Making. Rowman \& Littlefield Publishers, Totowa.

Kim, K.H., (2014). Counter-cyclical risk aversion. Journal of Empirical Finance 29, 384-401.

Koenker, R., (1981). A note on studentizing a test for heteroskedasticity. Journal of Econometrics 17, 107-112.

Lerner, J.S., and Keltner, D., (2001). Fear, anger and risk. Journal of Personality and Social Psychology 81, 146-159. 
Li, G., (2007). Time-varying risk aversion and asset prices. Journal of Banking and Finance 31, 243-257.

Lucas, R.E., (1978). Asset prices in an exchange economy. Econometrica 46, 1429-1445.

Malmendier, U., and Nagel, S., (2011). Depression babies: Do macroeconomic experiences affect risk taking? Quarterly Journal of Economics 126, 373-416.

Mankiw, N. G., and Shapiro, M.D., (1986). Do we reject too often? Economics Letters 20, 139-145.

Melino, A., and Yang, A.X., (2003). State-dependent preferences can explain the equity premium puzzle. Review of Economic Dynamics 6, 806-830.

Menzly, L., Santos, T., and Veronesi, P., (2004). Understanding predictability. Journal of Political Economy 112, 1-47.

Mehra, R., and Prescott, E.C., (1985). The equity premium: A puzzle. Journal of Monetary Economics 15, 145-161.

Merton, R.C., (1973). An inter-temporal capital asset pricing model. Econometrica 41, 867888.

Newey, W.K., and West, K.D., (1987). A simple, positive semi-definite, heteroskedasticity and autocorrelation consistent covariance matrix. Econometrica 55, 703-708.

Muir, T., (2017). Financial crises and risk premia. Quarterly Journal of Economics 132, 765809.

Necker, S., and Ziegelmeyer, M., (2016). Household risk taking after the financial crisis. The Quarterly Review of Economics and Finance 59, 141-160.

Poterba, J., and Summers, L.H., (1988). Mean reversion in stock returns: Evidence and implications. Journal of Financial Economics 22, 27-60.

Sahm, C.R., (2012). How much does risk tolerance change? Quarterly Journal of Finance 2, 138.

Schildberg-Hörisch, H., (2018). Are risk preferences stable? The Journal of Economic Perspectives 32, 135-154.

Schwert, G.W., (1990). Stock returns and real activity: A century of evidence. Journal of Finance 45, 1237-1257.

Shigeoka, H., (2019). Long-term consequences of growing up in a recession on risk preferences. NBER Working Paper 26352. 
Stambaugh, R.F., (1986). Bias in regression with lagged stochastic regressors. CRSP Working Paper No. 156, University of Chicago.

Wachter, J., (2006). A consumption-based model of the term structure of interest rates. Journal of Financial Economics 79, 365-399.

Weil, P., (1989). The equity premium puzzle and the risk-free rate puzzle. Journal of Monetary Economics 24, 401-421. 
Table 1. First-order autocorrelation of excess returns $r_{d, t+1}-r_{f, t+1}$

\begin{tabular}{ccc}
\hline First-Order autocorrelation & Q-Statistic & Probability \\
\hline 0.086 & 5.324 & 0.021 \\
\hline
\end{tabular}

Note: Q-Statistic is the Ljung-Box Q-Statistic and Probability is its p-value.

Table 2. The model selection

\begin{tabular}{cccccccccccc}
\hline $\mathrm{p}$ & 0 & 1 & 2 & 3 & 4 & 5 & 6 & 7 & 8 & 9 & 10 \\
\hline $\mathrm{AICc}$ & 4128 & 4110 & 4111 & 4115 & 4118 & 4120 & 4122 & 4123 & 4130 & 4136 & 4144 \\
\hline
\end{tabular}

Notes: (i) AICc is the corrected AIC of Hurvich and Tsai (1989) computed from regressions of $\mathrm{r}_{\mathrm{d}, \mathrm{t}+1}-$ $r_{f, t+1}$ on an intercept, $i_{s, t+1}$ and the past values $r_{d, t-h}-r_{f, t-h}, i_{s, t-h}, i_{L, t-h}, d p_{t-h}, \pi_{t-h}, i_{t-h}, m_{t-h}$ for $h=0,1,2$, $\ldots, p-1$ and $p=0,1, \ldots 10$. (ii) For $p=0, r_{d, t+1}-r_{f, t+1}$ is regressed on an intercept and $i_{s, t+1}$.

Table 3. Regression of $r_{d, t+1}-r_{f, t+1}$ on the candidate vector $x_{t}^{c}$

\begin{tabular}{cccc}
\hline & Coefficients & $\begin{array}{c}\mathrm{r}_{\mathrm{d}, \mathrm{t}+1}-\mathrm{r}_{\mathrm{f}, \mathrm{t}+1} \\
\mathrm{t}-\text { Statistics }\end{array}$ & p-values \\
\hline Intercept & $5.9157^{* *}$ & 2.2240 & 0.0265 \\
$\mathrm{i}_{\mathrm{S}, \mathrm{t}+1}$ & $-9.5810^{* *}$ & -2.5264 & 0.0117 \\
$\mathrm{i}_{\mathrm{S}, \mathrm{t}}$ & $6.7584^{*}$ & 1.7410 & 0.0821 \\
$\mathrm{dp}_{\mathrm{t}}$ & $1.3425^{* *}$ & 2.1895 & 0.0289 \\
$\mathrm{i}_{\mathrm{L}, \mathrm{t}}$ & 0.0802 & 0.4794 & 0.6317 \\
$\pi_{\mathrm{t}}$ & -0.5119 & -0.8581 & 0.3911 \\
$\mathrm{ip}_{\mathrm{t}}$ & -0.0520 & -0.5822 & 0.5606 \\
$\mathrm{~m}_{\mathrm{t}}$ & 0.0958 & 0.3472 & 0.7285 \\
$\mathrm{r}_{\mathrm{d}, \mathrm{t}}-\mathrm{r}_{\mathrm{f}, \mathrm{t}}$ & 0.0696 & 1.3746 & 0.1697 \\
\hline $\mathrm{R}^{2}=0.0385$ & &
\end{tabular}

Notes: (i) The coefficients are estimated by OLS with heteroskedasticity and autocorrelation consistent covariance matrix (Newey and West, 1987); (ii) ***,**, * means significance at 1\%, 5\%, and 10\% significance level.

Table 4. Homoskedasticity tests (conditionally to the candidate vector $x_{t}^{c}$ )

\begin{tabular}{ccccccc}
\hline & \multicolumn{2}{c}{$\begin{array}{c}\mathrm{r}_{\mathrm{d}, \mathrm{t}+1}-\mathrm{r}_{\mathrm{f}, \mathrm{t}+1} \\
(\mathrm{squared} \text { residual) }\end{array}$} & \multicolumn{2}{c}{$\begin{array}{c}\mathrm{r}_{\mathrm{d}, \mathrm{t}+1} \\
\text { (squared residual) }\end{array}$} & \multicolumn{2}{c}{$\begin{array}{c}\pi_{\mathrm{t}+1} \\
\text { (squared residual) }\end{array}$} \\
\cline { 2 - 7 } & Coefficients & $\mathrm{t}-$ Statistics & Coefficients & $\mathrm{t}$-Statistics & Coefficients & $\mathrm{t}$-Statistics \\
\hline Intercept & -7.7434 & -0.2882 & -7.2994 & -0.3502 & $0.1701^{* *}$ & 1.9996 \\
$\mathrm{i}_{\mathrm{S}, \mathrm{t}+1}$ & -0.5181 & -0.0134 & 2.5403 & 0.1057 & 0.0192 & 0.1958 \\
$\mathrm{i}_{\mathrm{S}, \mathrm{t}}$ & 4.0972 & 0.0842 & 1.9901 & 0.0826 & 0.0868 & 0.8830 \\
$\mathrm{dp}_{\mathrm{t}}$ & -5.4237 & -0.9046 & -5.3353 & -1.0997 & 0.0142 & 0.7202 \\
$\mathrm{i}_{\mathrm{L}, \mathrm{t}}$ & 0.8429 & 0.4270 & 0.7636 & 0.5402 & $-0.0141^{* *}$ & -2.4604 \\
$\pi_{\mathrm{t}}$ & -0.2180 & -0.0491 & 0.6111 & 0.1355 & -0.0144 & -0.7841 \\
$\mathrm{ip}_{\mathrm{t}}$ & -1.1575 & -1.4293 & -1.2013 & $-1.8710^{*}$ & $-0.0061^{* *}$ & -2.3401 \\
$\mathrm{~m}_{\mathrm{t}}$ & 2.8201 & 1.6386 & 2.7599 & 1.1616 & $0.0175^{*}$ & 1.8064 \\
$\mathrm{r}_{\mathrm{d}, \mathrm{t}}-\mathrm{r}_{\mathrm{f}, \mathrm{t}}$ & $-2.1012 * * *$ & -4.7595 & $-2.0443 * * *$ & -6.3541 & $-0.0035^{* * *}$ & -2.6755 \\
\hline Koenker & $\mathrm{TR}^{2} 47.8110$ & $\mathrm{p}-\mathrm{value}$ & $\mathrm{TR}^{2}$ & $\mathrm{p}-\mathrm{value}$ & $\mathrm{TR}^{2}$ & $\mathrm{p}$-value \\
test & & 0.0000 & 47.0287 & 0.0000 & 24.71253 & 0.0017 \\
\hline
\end{tabular}

Notes: (i) The coefficients are estimated by OLS with heteroskedasticity and autocorrelation consistent covariance matrix (Newey and West, 1987); (ii) ***,**,* means significance at 1\%, 5\%, and 10\% significance level; (iii) $\mathrm{TR}^{2}$ is the statistic of the homoskedasticity test (Koenker, 1981); (iv) A p-value less than $1 \%$ indicates that the homoskedasticity hypothesis is rejected at a significance level of $1 \%$. 


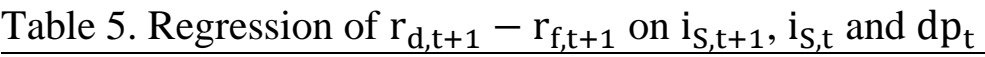

\begin{tabular}{cccc}
\hline & & $\mathrm{r}_{\mathrm{d}, \mathrm{t}+1}-\mathrm{r}_{\mathrm{f}, \mathrm{t}+1}$ \\
$\mathrm{t}-$ Statistics & $\mathrm{p}$-values \\
\hline Intercept & $6.5931^{* * *}$ & 2.7908 & 0.0054 \\
$\mathrm{i}_{\mathrm{S}, \mathrm{t}+1}$ & $-9.8384^{* *}$ & -2.5780 & 0.0101 \\
$\mathrm{i}_{\mathrm{S}, \mathrm{t}}$ & $7.2658^{*}$ & 1.9621 & 0.0501 \\
$\mathrm{dp}_{\mathrm{t}}$ & $1.4485^{* *}$ & 2.4462 & 0.0147 \\
\hline $\mathrm{R}^{2}=0.0301$ & & & \\
\hline
\end{tabular}

Notes: (i) The coefficients are estimated by OLS with heteroskedasticity and autocorrelation consistent covariance matrix (Newey and West, 1987); (ii) ***,**,* means significance at 1\%, 5\%, and 10\% significance level.

Table 6. Homoskedasticity tests (conditionally to $\mathrm{i}_{\mathrm{S}, \mathrm{t}+1}, \mathrm{i}_{\mathrm{S}, \mathrm{t}}$ and $\mathrm{dp} \mathrm{p}_{\mathrm{t}}$ )

\begin{tabular}{ccccccc}
\hline & \multicolumn{2}{c}{$\begin{array}{c}\mathrm{r}_{\mathrm{d}, \mathrm{t}+1}-\mathrm{r}_{\mathrm{f}, \mathrm{t}+1} \\
(\mathrm{squared} \text { residual) }\end{array}$} & \multicolumn{2}{c}{$\begin{array}{c}\mathrm{r}_{\mathrm{d}, \mathrm{t}+1} \\
\text { (squared residual) }\end{array}$} & \multicolumn{2}{c}{$\pi_{\mathrm{t}+1}$} \\
& Coefficients & $\mathrm{t}$-Statistics & Coefficients & $\mathrm{t}$-Statistics & Coefficients & $\mathrm{t}$-Statistics \\
\cline { 2 - 7 } Intercept & -5.0282 & -0.2155 & -5.7899 & -0.3084 & 0.2089 & $1.9105^{*}$ \\
$\mathrm{i}_{\mathrm{S}, \mathrm{t}+1}$ & 6.7079 & 0.1671 & 13.291 & 0.5551 & -0.1388 & -0.9949 \\
$\mathrm{i}_{\mathrm{S}, \mathrm{t}}$ & 8.3171 & 0.2278 & 3.2161 & 0.1337 & 0.1151 & 0.8219 \\
$\mathrm{dp}_{\mathrm{t}}$ & -4.9945 & -0.8857 & -5.1431 & -1.0904 & 0.0282 & 1.0291 \\
\hline Koenker & $\mathrm{TR}^{2}$ & $\mathrm{p}$-value & $\mathrm{TR}^{2}$ & $\mathrm{p}$-value & $\mathrm{TR}^{2}$ & $\mathrm{p}$-value \\
test & 4.3650 & 0.2246 & 5.4950 & 0.1389 & 1.9590 & 0.5809 \\
\hline
\end{tabular}

Notes: (i) The coefficients are estimated by OLS with heteroskedasticity and autocorrelation consistent covariance matrix (Newey and West, 1987); (ii) ***,**,* means significance at 1\%, 5\%, and 10\% significance level; (iii) $\mathrm{TR}^{2}$ is the statistic of the homoskedasticity test (Koenker, 1981); (iv) A p-value higher than 10\% indicates that the homoskedasticity hypothesis is not rejected at a significance level of $10 \%$.

Table 7. Test of the hypothesis $\mathrm{a}_{1}+\mathrm{a}_{2}=0$

\begin{tabular}{ccc}
\hline$\hat{\mathrm{a}}_{1}+\mathrm{a}_{2}$ & F-Statistic & P-value \\
\hline-2.5725 & 8.6161 & 0.0034 \\
\hline
\end{tabular}

Note: F-Statistic is the statistic of the Fisher test of the hypothesis $a_{1}+a_{2}=0$.

Table 8. Descriptive statistics of $\widehat{\mathrm{ra}}_{\mathrm{t}+1}$ and $\mathrm{r}_{\mathrm{d}, \mathrm{t}+1}-\mathrm{r}_{\mathrm{f}, \mathrm{t}+1}$

\begin{tabular}{c|ccccccc}
\hline & Mean & Median & $\begin{array}{c}\text { Maxim. } \\
\text { value }\end{array}$ & $\begin{array}{c}\text { Minim. } \\
\text { Value }\end{array}$ & $\begin{array}{c}\text { Standard } \\
\text { deviation }\end{array}$ & Skewness & Kurtosis \\
\hline$\hat{\mathrm{ra}}_{\mathrm{t}+1}$ & 0.4350 & 0.5631 & 3.5982 & -3.7560 & 0.7588 & -0.6523 & 5.8615 \\
\hline $\mathrm{r}_{\mathrm{d}, \mathrm{t}+1}-\mathrm{r}_{\mathrm{f}, \mathrm{t}+1}$ & 0.4354 & 0.8842 & 14.8577 & -26.2682 & 4.3662 & -0.7895 & 5.8235 \\
\hline
\end{tabular}

Table 9. First-order autocorrelation of the estimated risk aversion $\widehat{r a}_{t+1}$

\begin{tabular}{ccc}
\hline First-Order autocorrelation & Q-Statistic & Probability \\
\hline 0.424 & 129 & 0.000 \\
\hline
\end{tabular}

Note: Q-Statistic is the Ljung-Box Q-Statistic and Probability is its p-value. 
Table 10. Estimation of the state equation (18)

\begin{tabular}{cccc}
\hline & & $\mathrm{r}_{\mathrm{a}, \mathrm{t}+1}$ \\
$\mathrm{t}-$ Ctatistics & $\mathrm{p}$-values \\
\hline Intercept & $6.8489 * *$ & 2.3298 & 0.0198 \\
$\mathrm{ra}_{\mathrm{t}}$ & -0.0447 & -0.1333 & 0.8939 \\
$\mathrm{i}_{\mathrm{S}, \mathrm{t}+1}$ & $-9.8055^{* * *}$ & -4.6508 & 0.0000 \\
$\mathrm{i}_{\mathrm{S}, \mathrm{t}}$ & $7.1202^{* * *}$ & 2.6130 & 0.0090 \\
$\mathrm{dp}_{\mathrm{t}}$ & $2.9173 * * *$ & 74.436 & 0.0000 \\
\hline
\end{tabular}

Note: $* * *, * *, *$ means significance at $1 \%, 5 \%$, and $10 \%$ significance level.

Table 11. Estimation of the Taylor-rule equation (19)

\begin{tabular}{cccc}
\hline & & $\mathrm{i}_{\mathrm{S}, \mathrm{t}+1}$ \\
$\mathrm{t}-$ Statistics & $\mathrm{p}$-values \\
\hline Intercept & $0.0081^{* *}$ & 2.4899 & 0.0130 \\
$\mathrm{i}_{\mathrm{S}, \mathrm{t}}$ & $0.9618^{* * *}$ & 83.9939 & 0.0000 \\
$\mathrm{ip}_{\mathrm{t}}$ & $0.0027^{* *}$ & 2.5385 & 0.0113 \\
$\pi_{\mathrm{t}}$ & $0.0174^{* * *}$ & 2.7559 & 0.0060 \\
\hline $\mathrm{R}^{2}=0.9459$ & & &
\end{tabular}

Notes: (i) The coefficients are estimated by OLS with heteroskedasticity and autocorrelation consistent covariance matrix (Newey and West, 1987); (ii) ***,**,* means significance at $1 \%, 5 \%$, and $10 \%$ significance level.

Table 12. The dividend-price ratio model selection

\begin{tabular}{cccccccccccc}
\hline $\mathrm{p}$ & 0 & 1 & 2 & 3 & 4 & 5 & 6 & 7 & 8 & 9 & 10 \\
\hline $\mathrm{AICc}$ & -211 & $\mathbf{- 2 7 8 0}$ & -2769 & -2759 & -2757 & -2746 & -2740 & -2727 & -2709 & -2701 & -2695 \\
\hline
\end{tabular}

Notes: AICc is the corrected AIC of Hurvich and Tsai (1989) computed from the estimation of $\mathrm{dp}_{\mathrm{t}+1}$ in equation (20), where the unknown risk aversion $\mathrm{ra}_{\mathrm{t}+1}$ measure is replaced with the estimated risk aversion measure $\widehat{\mathrm{ra}}_{\mathrm{t}+1}$ drawn from univariate analysis of section 3 .

Table 13. Estimation of the dividend-price ratio equation

\begin{tabular}{cccc}
\hline & & $\mathrm{dp}_{\mathrm{t}+1}$ & \\
& Coefficients & $\mathrm{t}$-Statistics & $\mathrm{p}$-values \\
\hline Intercept & $-4.5458^{* * *}$ & 940.2287 & 0.0000 \\
$\widehat{\mathrm{ra}}_{\mathrm{t}+1}$ & $0.6828^{* * *}$ & 120.1724 & 0.0000 \\
$\widehat{\mathrm{r}}_{\mathrm{t}}$ & -0.0022 & -0.6709 & 0.5024 \\
$\mathrm{i}_{\mathrm{S}, \mathrm{t}+1}$ & $6.8088^{* * *}$ & 101.0298 & 0.0000 \\
$\mathrm{i}_{\mathrm{S}, \mathrm{t}}$ & $-5.0389^{* * *}$ & -77.8196 & 0.0000 \\
$\mathrm{AR}$ term $\left(\varphi_{1}\right)$ & $0.2716^{* * *}$ & 7.0346 & 0.0000 \\
\hline $\mathrm{R}^{2}=0.9924$ & & &
\end{tabular}

Notes: (i) The coefficients are estimated by nonlinear least squares with heteroskedasticity and autocorrelation consistent covariance matrix (Newey and West, 1987); (ii) ***,**,* means significance at $1 \%, 5 \%$, and $10 \%$ significance level. 
Table 14. Estimation of the equation system

\begin{tabular}{ccccccc}
\hline & \multicolumn{2}{c}{$\mathrm{r}_{\mathrm{d}, \mathrm{t}+1}-\mathrm{r}_{\mathrm{f}, \mathrm{t}+1}$} & \multicolumn{2}{c}{$\mathrm{i}_{\mathrm{S}, \mathrm{t}+1}$} & \multicolumn{2}{c}{$\mathrm{dp}_{\mathrm{t}+1}$} \\
\cline { 2 - 6 } & Coefficients & $\mathrm{t}-$ Statistics & Coefficients & $\mathrm{t}$-Statistics & Coefficients & $\mathrm{t}-$ Statistics \\
\hline Intercept & $6.5931^{* * *}$ & 2.7908 & $0.0081^{* *}$ & 2.4899 & $-4.5458^{* * *}$ & -14.3578 \\
$\mathrm{i}_{\mathrm{S}, \mathrm{t}+1}$ & $-9.8384^{* *}$ & -2.5780 & & & $6.8154^{*}$ & 1.8934 \\
$\mathrm{i}_{\mathrm{S}, \mathrm{t}}$ & $7.2658^{*}$ & 1.9621 & $0.9618^{* * *}$ & 83.9939 & -5.0455 & -1.5110 \\
$\mathrm{dp}_{\mathrm{t}}$ & $1.4485^{* *}$ & 2.4462 & & & & \\
$\mathrm{ip}_{\mathrm{t}}$ & & & $0.0027 * *$ & 2.5385 & & \\
$\mathrm{~T}_{\mathrm{t}}$ & & & $0.0174 * * *$ & 2.7559 & & \\
$\mathrm{ra}_{\mathrm{t}+1}$ & & & & & $0.6834 * *$ & 2.4237 \\
$\mathrm{ra}_{\mathrm{t}}$ & & & & & -0.0027 & -0.8575 \\
$\mathrm{AR} \mathrm{term}$ & & & & & $0.2715^{* * *}$ & 7.0394 \\
\hline
\end{tabular}

Notes: (i) The coefficients are estimated by GMM with heteroskedasticity and autocorrelation consistent covariance matrix (Newey and West, 1987); (ii) ***, **, * means significance at 1\%, 5\%, and $10 \%$ significance level.

Table 15. Test of the hypothesis $\frac{a_{1}+a_{2}+a_{3}\left(e_{0}+e_{1}\right)}{1-a_{3} d_{0}}=0$

\begin{tabular}{ccc}
\hline$\frac{\hat{a}_{1}+\hat{a}_{2}+\hat{a}_{3}\left(\hat{e}_{0}+\hat{e}_{1}\right)}{1-\hat{a}_{3} \hat{d}_{0}}$ & Chi-square Statistic & P-value \\
\hline-0.8789 & & 0.1687 \\
\hline
\end{tabular}

Note: Chi-square Statistic is the statistic of the Wald test of the hypothesis $\frac{a_{1}+a_{2}+a_{3}\left(e_{0}+e_{1}\right)}{1-a_{3} d_{0}}=0$. 
Figure 1. The risk aversion measure $\widehat{r a}_{t+1}$.

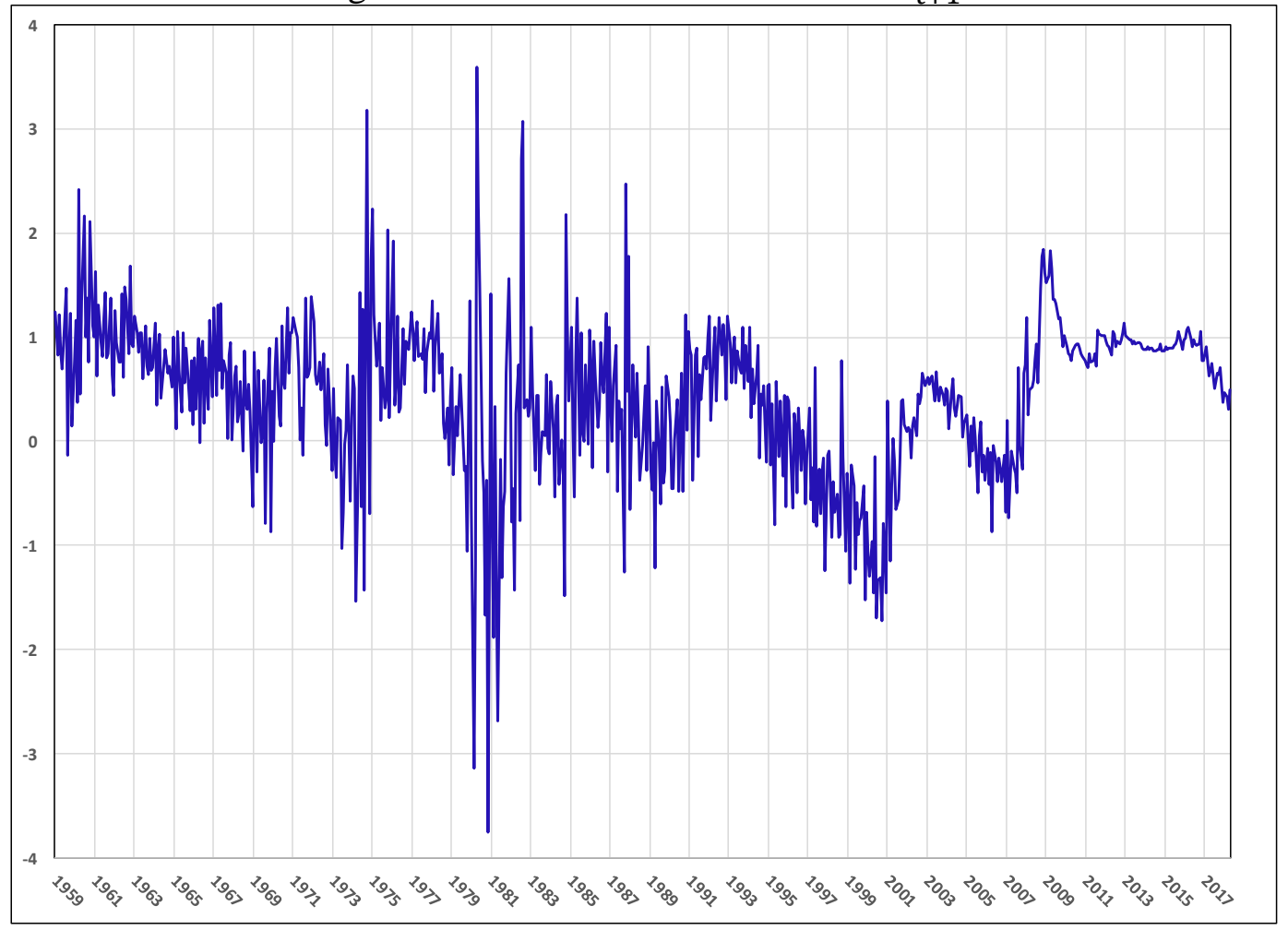

Figure 2. The interest rate component and the risk aversion

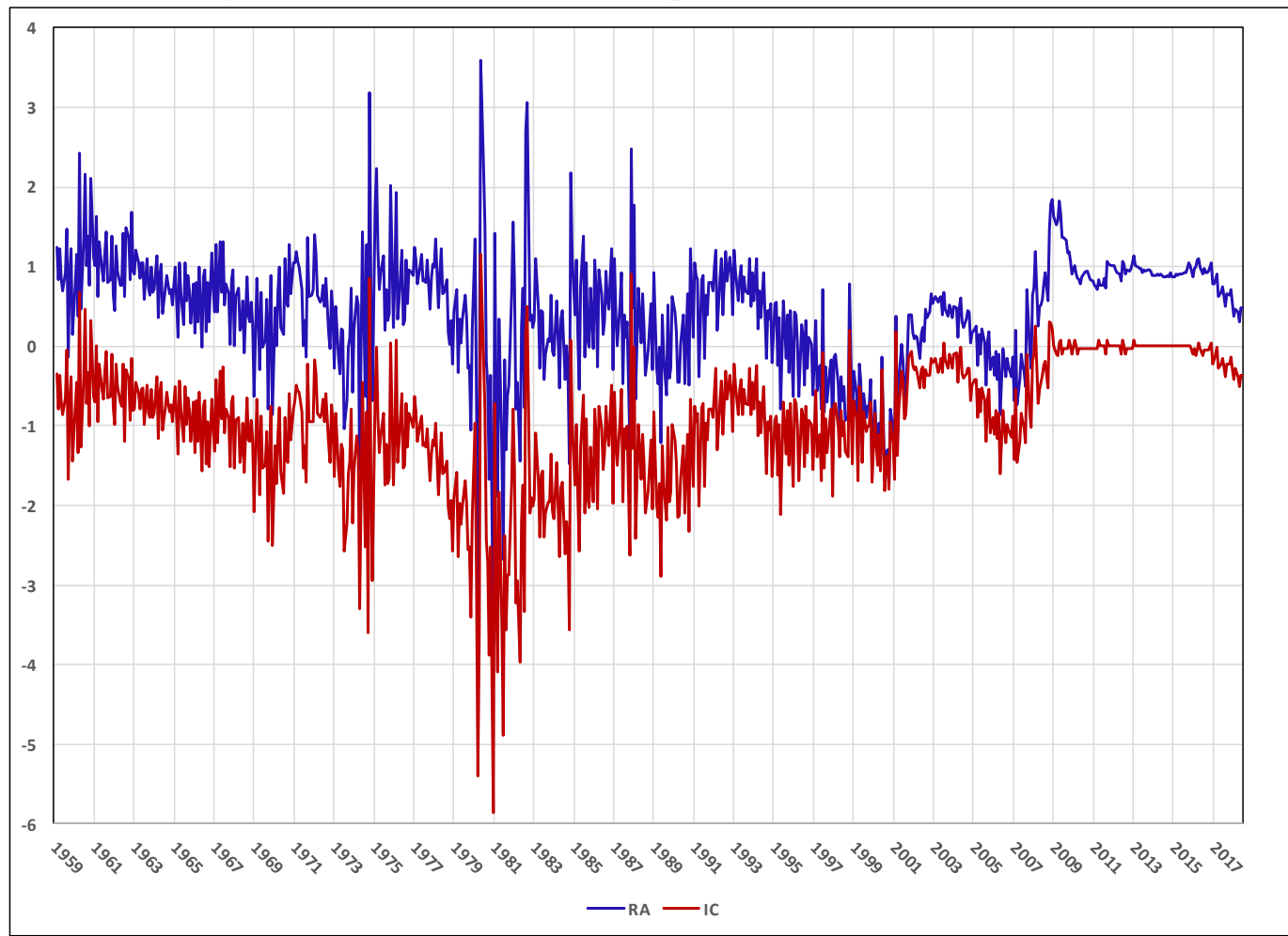

Note: The interest rate component is defined as $\mathrm{ic}_{\mathrm{t}+1}=\hat{\mathrm{a}}_{1} \mathrm{i}_{\mathrm{s}, \mathrm{t}+1}+\hat{\mathrm{a}}_{2} \mathrm{i}_{\mathrm{s}, \mathrm{t}}$. 
Figure 3. The dividend-price component and the risk aversion

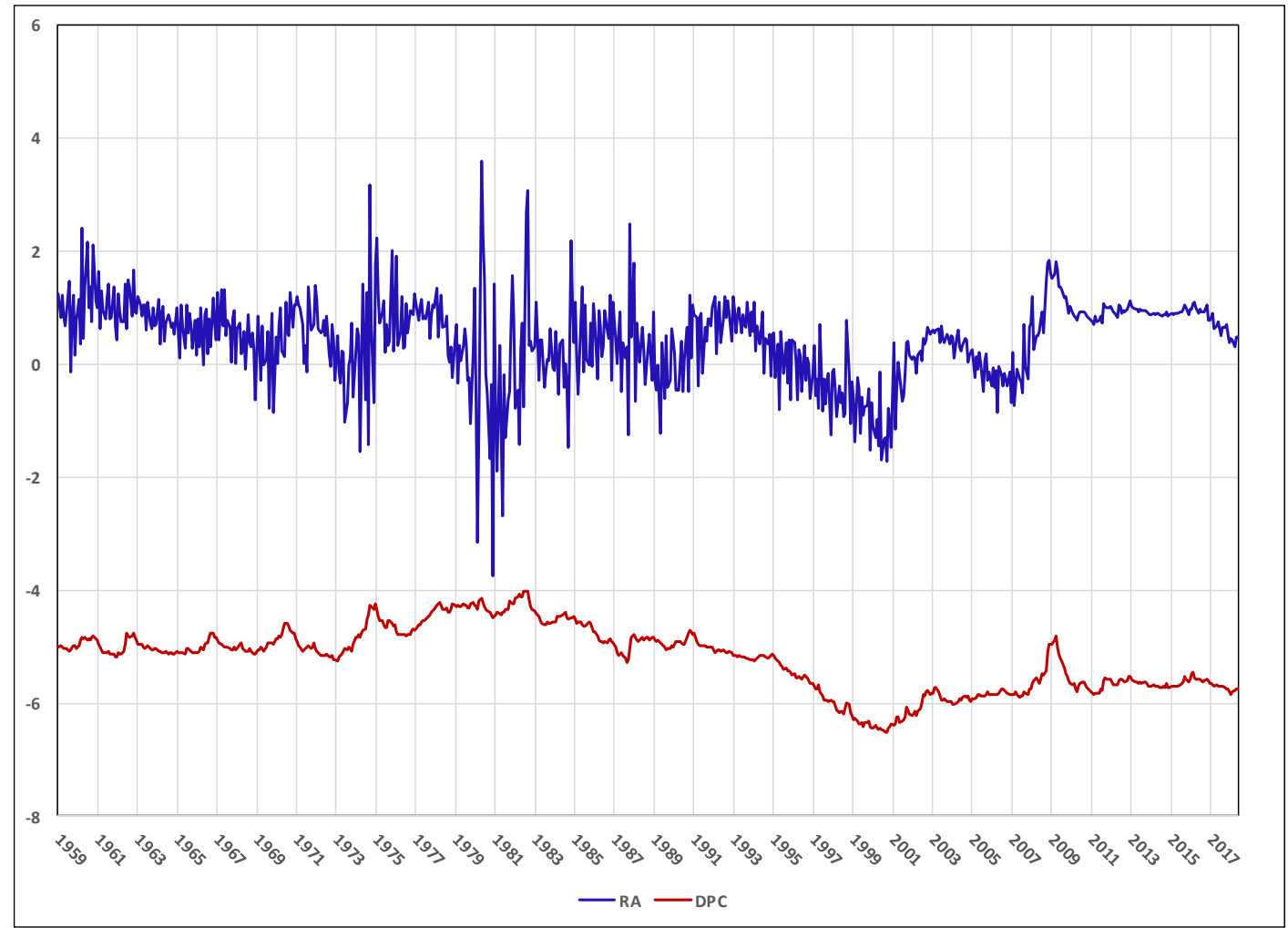

Note: The dividend-price component is defined as $d p c_{t+1}=\hat{a}_{0}+\hat{a}_{3} d p_{t}$.

Figure 4. The NBER recession indicator and the risk aversion

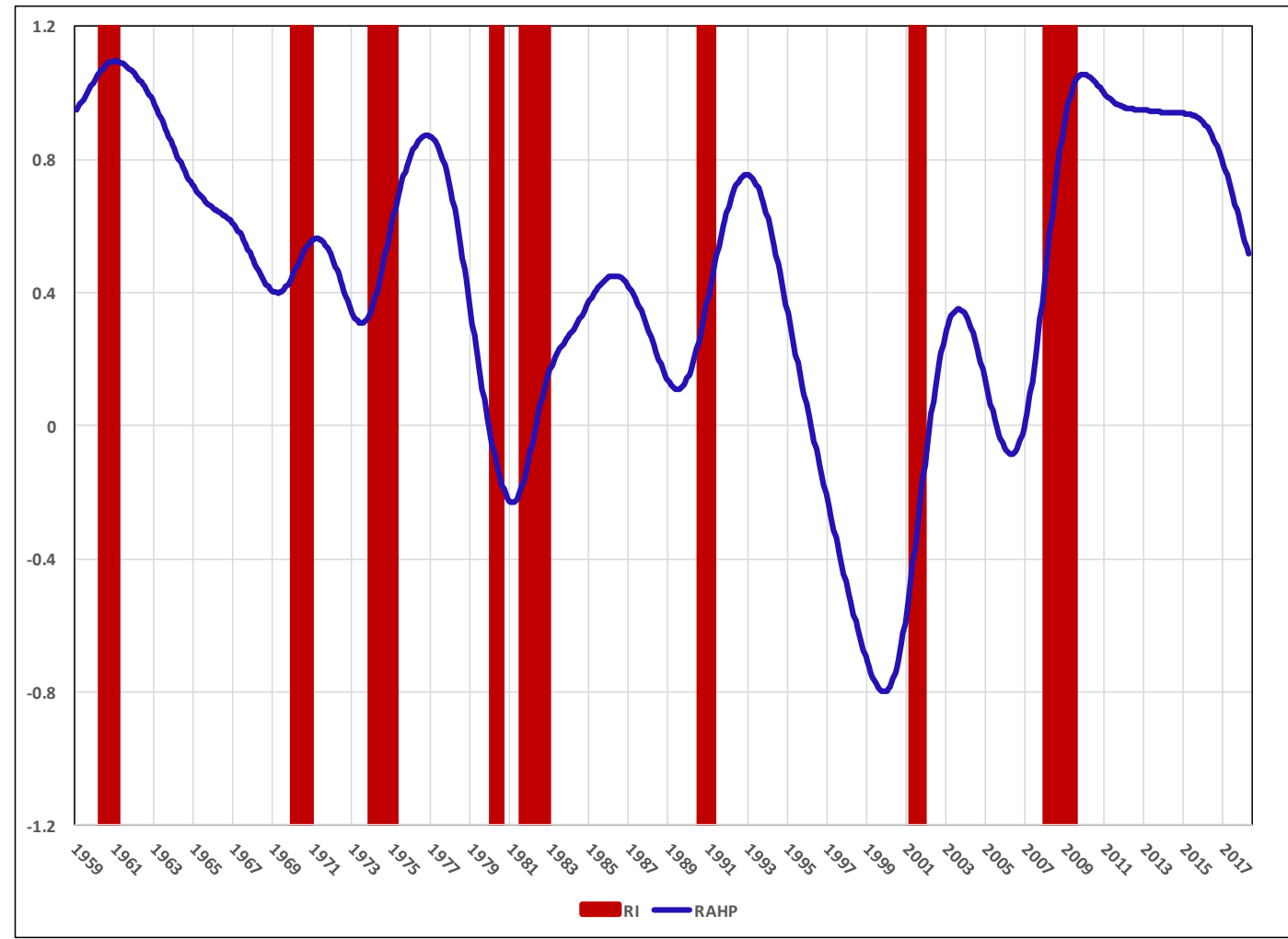

Note : RI is for the NBER recession indicator and RAHP is for the risk aversion smoothed with the HoldrickPrescott filter. A value of 1 for RI is a recessionary period, while a value of 0 is an expansionary period. 
Figure 5. Response of risk aversion to a shock on the dividend-price ratio innovation

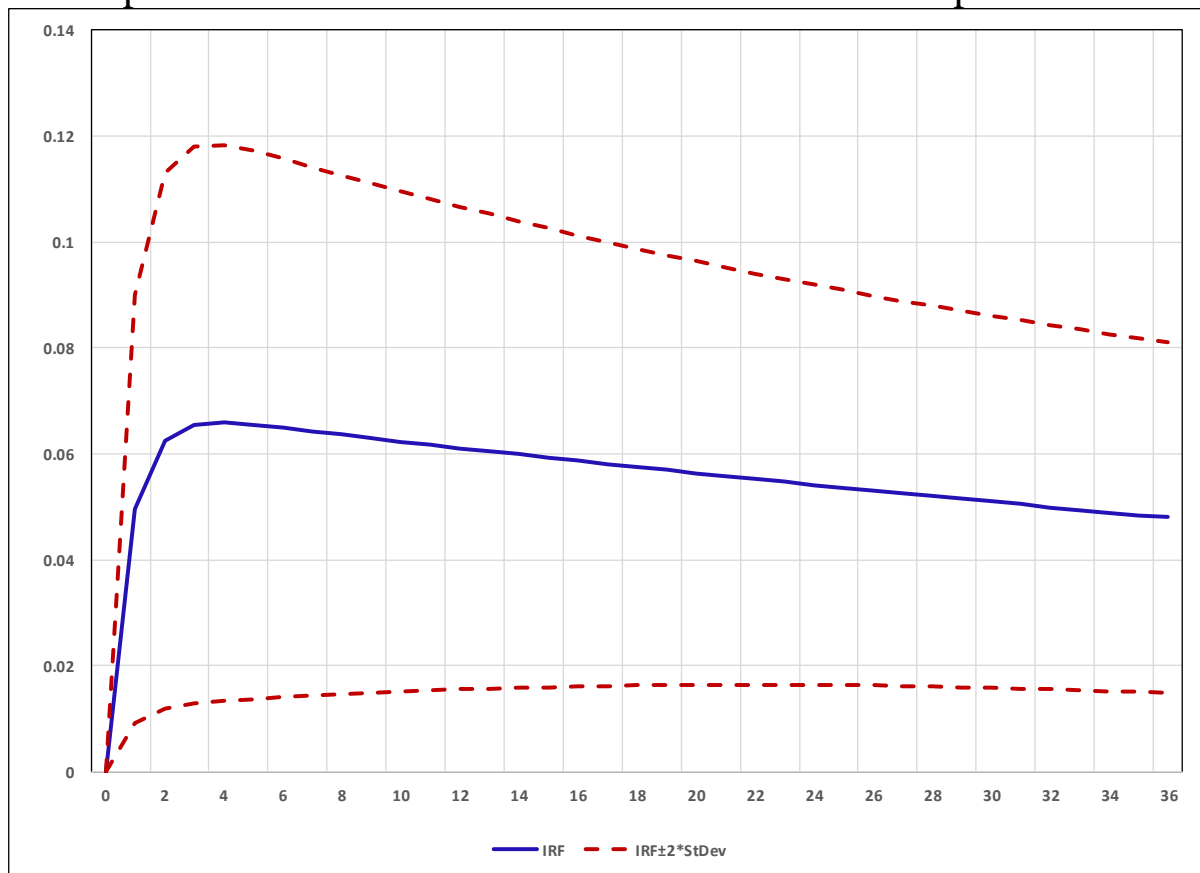

Notes: (i) The Impulse Response Function (IRF) is evaluated for a shock on the innovation equal to the standard

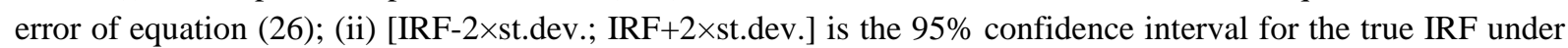
normality of the estimated IRF.

Figure 6. Response of risk aversion to a shock on the interest rate innovation

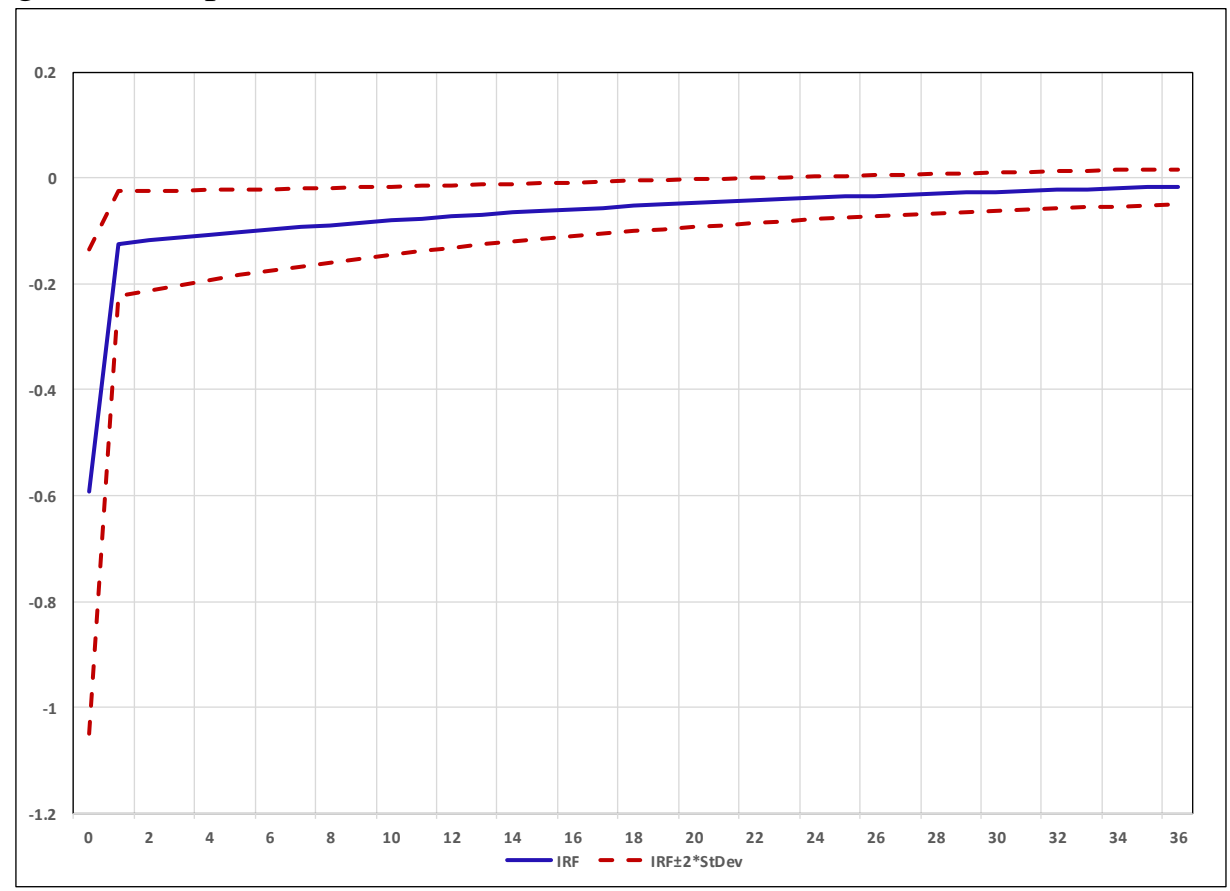

Notes: (i) The Impulse Response Function (IRF) is evaluated for a shock on the innovation equal to the standard

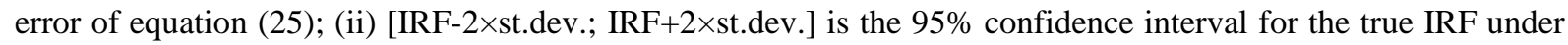
normality of the estimated IRF. 


\section{Appendix : The Impulse Response Functions}

The system consists of equations (23) to (25) with the restriction that $d_{1}=0$ :

$$
\begin{aligned}
\mathrm{ra}_{\mathrm{t}+1} & =\mathrm{a}_{0}+\mathrm{a}_{1} \mathrm{i}_{\mathrm{S}, \mathrm{t}+1}+\mathrm{a}_{2} \mathrm{i}_{\mathrm{s}, \mathrm{t}}+\mathrm{a}_{3} \mathrm{dp}_{\mathrm{t}}, \\
\mathrm{i}_{\mathrm{S}, \mathrm{t}+1} & =\mathrm{b}_{0}+\mathrm{b}_{1} \mathrm{i}_{\mathrm{S}, \mathrm{t}}+\mathrm{b}_{2} \mathrm{ip}_{\mathrm{t}}+\mathrm{b}_{3} \pi_{\mathrm{t}}+\mathrm{u}_{\mathrm{t}+1}, \\
\mathrm{dp}_{\mathrm{t}+1} & =\mathrm{c}+\mathrm{d}_{0} \mathrm{ra}_{\mathrm{t}+1}+\mathrm{e}_{0} \mathrm{i}_{\mathrm{S}, \mathrm{t}+1}+\mathrm{e}_{1} \mathrm{i}_{\mathrm{s}, \mathrm{t}}+\varepsilon_{\mathrm{t}+1}, \\
\varepsilon_{\mathrm{t}+1} & =\varphi_{1} \varepsilon_{\mathrm{t}}+\eta_{\mathrm{t}+1} .
\end{aligned}
$$

1) The impulse response function $\frac{\partial \mathrm{ra}_{\mathrm{t}+\mathrm{k}}}{\partial \eta_{\mathrm{t}}}$

The response of risk aversion to a unit shock in the dividend-price ratio is:

$\frac{\partial \mathrm{ra}_{\mathrm{t}+\mathrm{k}}}{\partial \eta_{\mathrm{t}}}=0$ for $\mathrm{k}=0$ and $\frac{\partial \mathrm{ra}_{\mathrm{t}+\mathrm{k}}}{\partial \eta_{\mathrm{t}}}=\mathrm{a}_{3} \frac{\left(\mathrm{a}_{3} \mathrm{~d}_{0}\right)^{\mathrm{k}}-\varphi_{1}^{k}}{\mathrm{a}_{3} \mathrm{~d}_{0}-\varphi_{1}}$ for $\mathrm{k} \geq 1$

Evidently, $\frac{\partial \mathrm{ra}_{\mathrm{t}+\mathrm{k}}}{\partial \eta_{\mathrm{t}}}=0$ for $\mathrm{k}=0$ as the current dividend price rate does not affect risk aversion.

For $\mathrm{k} \geq 1$, it follows from equations (A1) and (A3) that

$$
\frac{\partial \mathrm{ra}_{\mathrm{t}+\mathrm{k}}}{\partial \eta_{\mathrm{t}}}=\mathrm{a}_{3} \frac{\partial \mathrm{dp}_{\mathrm{t}+\mathrm{k}-1}}{\partial \eta_{\mathrm{t}}}=\mathrm{a}_{3}\left(\mathrm{~d}_{0} \frac{\partial \mathrm{ra}_{\mathrm{t}+\mathrm{k}-1}}{\partial \eta_{\mathrm{t}}}+\frac{\partial \varepsilon_{\mathrm{t}+\mathrm{k}-1}}{\partial \eta_{\mathrm{t}}}\right)=\mathrm{a}_{3} \mathrm{~d}_{0} \frac{\partial \mathrm{ra}_{\mathrm{t}+\mathrm{k}-1}}{\partial \eta_{\mathrm{t}}}+\mathrm{a}_{3} \varphi_{1}^{k-1}
$$

By developing (A4), we find that

$$
\begin{gathered}
\frac{\partial \mathrm{ra}+\mathrm{k}}{\partial \eta_{\mathrm{t}}}=\left(\mathrm{a}_{3} \mathrm{~d}_{0}\right)^{\mathrm{k}-1} \frac{\partial \mathrm{ra} \mathrm{t}_{\mathrm{t} 1}}{\partial \eta_{\mathrm{t}}}+\mathrm{a}_{3}\left[\left(\mathrm{a}_{3} \mathrm{~d}_{0}\right)^{\mathrm{k}-2} \varphi_{1}+\left(\mathrm{a}_{3} \mathrm{~d}_{0}\right)^{\mathrm{k}-3} \varphi_{1}^{2}+\left(\mathrm{a}_{3} \mathrm{~d}_{0}\right)^{\mathrm{k}-4} \varphi_{1}^{3}+\cdots+\right. \\
\left.\left(\mathrm{a}_{3} \mathrm{~d}_{0}\right)^{2} \varphi_{1}^{\mathrm{k}-3}+\mathrm{a}_{3} \mathrm{~d}_{0} \varphi_{1}^{\mathrm{k}-2}+\varphi_{1}^{\mathrm{k}-1}\right]
\end{gathered}
$$

It follows immediately from equations (A1) and (A3) that $\frac{\partial \mathrm{ra}_{\mathrm{t}+\mathrm{k}}}{\partial \eta_{\mathrm{t}}}=\mathrm{a}_{3}$ for $\mathrm{k}=1$. Thus, equation (A5) can be written more compactly:

$$
\begin{aligned}
\frac{\partial r a_{t+k}}{\partial \eta_{t}} & =a_{3}\left(a_{3} d_{0}\right)^{k-1}\left[1+\frac{\varphi_{1}}{a_{3} d_{0}}+\left(\frac{\varphi_{1}}{a_{3} d_{0}}\right)^{2}+\cdots+\left(\frac{\varphi_{1}}{a_{3} d_{0}}\right)^{k-1}\right] \\
& =a_{3}\left(a_{3} d_{0}\right)^{k-1} \frac{1-\left(\frac{\varphi_{1}}{a_{3} d_{0}}\right)^{k}}{1-\frac{\varphi_{1}}{a_{3} d_{0}}},
\end{aligned}
$$

since we assume that $\left|\frac{\varphi_{1}}{\mathrm{a}_{3} \mathrm{~d}_{0}}\right|<1$, or equivalently 


$$
\frac{\partial \mathrm{ra}_{\mathrm{t}+\mathrm{k}}}{\partial \eta_{\mathrm{t}}}=\mathrm{a}_{3} \frac{\left(\mathrm{a}_{3} \mathrm{~d}_{0}\right)^{\mathrm{k}}-\varphi_{1}^{k}}{\mathrm{a}_{3} \mathrm{~d}_{0}-\varphi_{1}}
$$

2) The impulse response function $\frac{\partial \mathrm{ra}_{\mathrm{t}+\mathrm{k}}}{\partial \mathrm{u}_{\mathrm{t}}}$

The response of risk aversion to a unit shock in the short-term interest rate is:

$\frac{\partial \mathrm{ra}_{\mathrm{t}+\mathrm{k}}}{\partial \mathrm{u}_{\mathrm{t}}}=\mathrm{a}_{1}$ for $\mathrm{k}=0$ and $\frac{\partial \mathrm{ra}_{\mathrm{t}+\mathrm{k}}}{\partial \mathrm{u}_{\mathrm{t}}}=\mathrm{a}_{1}\left(\mathrm{~b}_{1}\right)^{\mathrm{k}}+\mathrm{a}_{2}\left(\mathrm{~b}_{1}\right)^{\mathrm{k}-1}+\mathrm{a}_{3}\left(\mathrm{a}_{1} \mathrm{~d}_{0}+\mathrm{e}_{0}\right) \frac{\left(\mathrm{a}_{3} \mathrm{~d}_{0}\right)^{\mathrm{k}}-\left(\mathrm{b}_{1}\right)^{\mathrm{k}}}{\mathrm{a}_{3} \mathrm{~d}_{0}-\mathrm{b}_{1}}+$ $a_{3}\left(a_{2} d_{0}+e_{1}\right) \frac{\left(a_{3} d_{0}\right)^{k-1}-\left(b_{1}\right)^{k-1}}{a_{3} d_{0}-b_{1}}$ for $k \geq 1$

It follows immediately from equations (A1) and (A2) that $\frac{\partial r a_{t+k}}{\partial u_{t}}=a_{1}$ for $k=0$.

For $\mathrm{k} \geq 1$, equation (A1) implies that

$$
\frac{\partial \mathrm{ra}_{\mathrm{t}+\mathrm{k}}}{\partial \mathrm{u}_{\mathrm{t}}}=\mathrm{a}_{1} \frac{\partial \mathrm{i}_{\mathrm{s}, \mathrm{t}+\mathrm{k}}}{\partial \mathrm{u}_{\mathrm{t}}}+\mathrm{a}_{2} \frac{\partial \mathrm{i}_{\mathrm{s}, \mathrm{t}+\mathrm{k}-1}}{\partial \mathrm{u}_{\mathrm{t}}}+\mathrm{a}_{3} \frac{\partial \mathrm{dp}_{\mathrm{t}+\mathrm{k}-1}}{\partial \mathrm{u}_{\mathrm{t}}}
$$

From equation (A2), it is straightforward to show that

$$
\frac{\partial \mathrm{i}_{\mathrm{s}, \mathrm{t}+\mathrm{k}}}{\partial \mathrm{u}_{\mathrm{t}}}=\mathrm{b}_{1}^{\mathrm{k}} \text { and, thus, } \frac{\partial \mathrm{i}_{\mathrm{s}, \mathrm{t}+\mathrm{k}-1}}{\partial \mathrm{u}_{\mathrm{t}}}=\mathrm{b}_{1}^{\mathrm{k}-1}
$$

From equation (A3),

$$
\frac{\partial \mathrm{dp}_{\mathrm{t}+\mathrm{k}}}{\partial \mathrm{u}_{\mathrm{t}}}=\mathrm{d}_{0} \frac{\partial \mathrm{ra} \mathrm{t}_{\mathrm{t}+\mathrm{k}}}{\partial \mathrm{u}_{\mathrm{t}}}+\mathrm{e}_{0} \frac{\partial \mathrm{i}_{\mathrm{s}, \mathrm{t}+\mathrm{k}}}{\partial \mathrm{u}_{\mathrm{t}}}+\mathrm{e}_{1} \frac{\partial \mathrm{i}_{\mathrm{s}, \mathrm{t}+\mathrm{k}-1}}{\partial \mathrm{u}_{\mathrm{t}}}
$$

Substituting equations (A8) and (A9) into equation (A10), we find that

$$
\frac{\partial \mathrm{dp}_{\mathrm{t}+\mathrm{k}}}{\partial \mathrm{u}_{\mathrm{t}}}=\mathrm{a}_{3} \mathrm{~d}_{0} \frac{\partial \mathrm{dp_{ \textrm {t } + \mathrm { k } - 1 }}}{\partial \mathrm{u}_{\mathrm{t}}}+\left(\mathrm{a}_{1} \mathrm{~d}_{0}+\mathrm{e}_{0}\right) \mathrm{b}_{1}^{\mathrm{k}}+\left(\mathrm{a}_{2} \mathrm{~d}_{0}+\mathrm{e}_{1}\right) \mathrm{b}_{1}^{\mathrm{k}-1}
$$

Let's denote $h_{k}=\left(a_{3} d_{0}\right)^{k-1}+\left(a_{3} d_{0}\right)^{k-2} b_{1}+\left(a_{3} d_{0}\right)^{k-3} b_{1}^{2}+\cdots+a_{3} d_{0} b_{1}^{k-2}+b_{1}^{k-1}$. By developing equation (A11), we find that

$$
\frac{\partial d p_{t+k}}{\partial u_{t}}=\left(a_{3} d_{0}\right)^{k} \frac{\partial d p_{t}}{\partial u_{t}}+\left(a_{1} d_{0}+e_{0}\right) b_{1} h_{k}+\left(a_{2} d_{0}+e_{1}\right) h_{k}
$$

From equations (A1), (A2), and (A3), it follows than the initial condition of this difference equation is

$$
\frac{\partial \mathrm{dp}_{\mathrm{t}}}{\partial \mathrm{u}_{\mathrm{t}}}=\mathrm{a}_{1} \mathrm{~d}_{0}+\mathrm{e}_{0}
$$

Note that $h_{k}$ can be written more compactly as 


$$
\begin{aligned}
h_{k} & =\left(a_{3} d_{0}\right)^{k-1}\left[1+\frac{b_{1}}{a_{3} d_{0}}+\left(\frac{b_{1}}{a_{3} d_{0}}\right)^{2}+\cdots+\left(\frac{b_{1}}{a_{3} d_{0}}\right)^{k-2}+\left(\frac{b_{1}}{a_{3} d_{0}}\right)^{k-1}\right] \\
& =\frac{\left(a_{3} d_{0}\right)^{k}-\left(b_{1}\right)^{k}}{a_{3} d_{0}-b_{1}}
\end{aligned}
$$

since we assume that $\left|\frac{b_{1}}{a_{3} d_{0}}\right|<1$. Substituting equations (A14) and (A13) into equation (A12), we get

$$
\begin{gathered}
\frac{\partial d p_{t+k}}{\partial u_{t}}=\left(a_{3} d_{0}\right)^{k}\left(a_{1} d_{0}+e_{0}\right)+\left(a_{1} d_{0}+e_{0}\right) b_{1} \frac{\left(a_{3} d_{0}\right)^{k}-\left(b_{1}\right)^{k}}{a_{3} d_{0}-b_{1}}+ \\
\left(a_{2} d_{0}+e_{1}\right) \frac{\left(a_{3} d_{0}\right)^{k}-\left(b_{1}\right)^{k}}{a_{3} d_{0}-b_{1}}
\end{gathered}
$$

Substituting equations (A9) and (A15) into equation (A8), we find

$$
\begin{aligned}
& \frac{\partial r a_{t+k}}{\partial u_{t}}=a_{1} b_{1}^{k}+a_{2} b_{1}^{k-1}+a_{3}\left(a_{3} d_{0}\right)^{k-1}\left(a_{1} d_{0}+e_{0}\right)+ \\
& \quad\left(a_{1} d_{0}+e_{0}\right) a_{3} b_{1} \frac{\left(a_{3} d_{0}\right)^{k-1}-\left(b_{1}\right)^{k-1}}{a_{3} d_{0}-b_{1}}+\left(a_{2} d_{0}+e_{1}\right) a_{3} \frac{\left(a_{3} d_{0}\right)^{k-1}-\left(b_{1}\right)^{k-1}}{a_{3} d_{0}-b_{1}}
\end{aligned}
$$

After rearrangement,

$$
\begin{aligned}
& \frac{\partial \mathrm{ra} \mathrm{a}_{\mathrm{t}+\mathrm{k}}}{\partial \mathrm{u}_{\mathrm{t}}}=\mathrm{a}_{1} \text { for } \mathrm{k}=0 \text { and } \\
& \qquad \begin{aligned}
\frac{\partial \mathrm{ra} \mathrm{a}_{\mathrm{t}+\mathrm{k}}}{\partial \mathrm{u}_{\mathrm{t}}}=\mathrm{a}_{1}\left(\mathrm{~b}_{1}\right)^{\mathrm{k}}+\mathrm{a}_{2}\left(\mathrm{~b}_{1}\right)^{\mathrm{k}-1}+\mathrm{a}_{3}\left(\mathrm{a}_{1} \mathrm{~d}_{0}+\mathrm{e}_{0}\right) \frac{\left(\mathrm{a}_{3} \mathrm{~d}_{0}\right)^{\mathrm{k}}-\left(\mathrm{b}_{1}\right)^{\mathrm{k}}}{\mathrm{a}_{3} \mathrm{~d}_{0}-\mathrm{b}_{1}}+ \\
\qquad \mathrm{a}_{3}\left(\mathrm{a}_{2} \mathrm{~d}_{0}+\mathrm{e}_{1}\right) \frac{\left(\mathrm{a}_{3} \mathrm{~d}_{0}\right)^{\mathrm{k}-1}-\left(\mathrm{b}_{1}\right)^{\mathrm{k}-1}}{\mathrm{a}_{3} \mathrm{~d}_{0}-\mathrm{b}_{1}} \text { for } \mathrm{k} \geq 1 .
\end{aligned}
\end{aligned}
$$

